\title{
DROGAS DE ABUSO EM ÁGUAS NATURAIS E RESIDUÁRIAS URBANAS: OCORRÊNCIA, DETERMINAÇÃO E APLICAÇÕES FORENSES
}

\author{
Rafael Silva Feitosa e Fernando Fabriz Sodré* \\ Instituto de Química, Universidade de Brasília, CP 4478, 70910-900 Brasília - DF, Brasil \\ Adriano Otávio Maldaner \\ Instituto Nacional de Criminalística, Polícia Federal, SAIS Quadra 07 Lote 23, 70610-200 Brasília - DF, Brasil
}

Recebido em 4/6/12; aceito em 29/8/12; publicado na web em 6/2/13

\begin{abstract}
DRUGS OF ABUSE IN WATERS AND WASTEWATERS: OCCURRENCE, ANALYTICAL DETERMINATION AND FORENSIC APPLICATIONS. Drugs of abuse are commonly used outside medical or legal settings where their production, marketing and consumption are subject to legal summons and/or intervention. Classified as emerging contaminants, these substances have been recently detected in samples of environmental concern, such as waters and wastewaters. This review presents the state-of-the-art on the methodological approaches used in sample preparation, the main techniques applied in analytical determination at trace levels, as well as the use of information related to the drug or its metabolite concentration in sewage samples to empirically estimate the consumption of drugs of abuse in a city or region.
\end{abstract}

Keywords: emerging contaminants; drugs of abuse; sewage epidemiology.

\section{INTRODUÇÃO}

Há pelo menos duas décadas, a presença de diversas substâncias orgânicas naturais e sintéticas no ambiente, dentre as quais fármacos, produtos de higiene pessoal e hormônios sexuais, têm chamado a atenção da comunidade científica e regulatória devido aos potenciais riscos que podem trazer ao ambiente e à saúde humana e/ou animal. ${ }^{1}$ Conhecidas como contaminantes emergentes, tais substâncias não estão contempladas, de maneira explícita, em nenhuma legislação ambiental. ${ }^{2}$ Contaminantes emergentes podem ser encontrados em diferentes compartimentos ambientais e, na grande maioria das vezes, sob níveis de concentração traço, ou seja, menores que uma parte por bilhão. Contudo, mesmo nestas concentrações, inúmeras evidências mostram que substâncias classificadas como emergentes podem efetivamente impactar ecossistemas, causando efeitos que vão desde a bioconcentração até a interferência no sistema endócrino de organismos vivos. ${ }^{3}$

Nos últimos anos, pesquisas colocaram em evidência um novo grupo de contaminantes emergentes constituído por drogas de abuso e substâncias psicotrópicas, cuja produção, comercialização e consumo são proibidos ou, em alguns países, objeto de controle. ${ }^{4-8}$ Parte dessas substâncias, inalteradas ou sob a forma de metabólitos, é excretada através da urina e das fezes alcançando, invariavelmente, diferentes compartimentos ambientais.

Apesar das drogas de abuso apresentarem, comprovadamente, efeitos psicotrópicos e, muitas vezes, tóxicos frente aos seres humanos, ainda não existem estudos ecotoxicológicos a respeito dessas substâncias. ${ }^{6-8}$ Entretanto, suspeita-se que possam provocar efeitos deletérios sobre ecossistemas contaminados, tal qual tem sido observado em estudos ecotoxicológicos envolvendo drogas lícitas, como produtos farmacêuticos e/ou mistura de fármacos. ${ }^{9}$ Outro motivo de preocupação reside no fato destas substâncias terem se tornado contaminantes pseudopersistentes, definição esta que surge em função de sua grande produção e consumo perene. ${ }^{8}$

Segundo o World Drug Report, ${ }^{10}$ publicado pelo Escritório das Nações Unidas sobre Drogas e Crime, a quantidade de usuários de

*e-mail: ffsodre@unb.br drogas de abuso tem aumentado desde a década de 1990. Foi estimado que o número de pessoas que consumiram drogas de uso controlado ou proibido pelo menos uma vez, entre 2009 e 2010, possa chegar a 272 milhões, o que corresponde a $6,1 \%$ da população mundial com idade entre 15 e 64 anos. ${ }^{10}$ Ainda, de acordo com o mesmo relatório, os usuários de cannabis - termo genérico referente aos vários produtos derivados da planta de maconha (Cannabis sativa L.) - compreendem o maior número de usuários. Os consumidores de anfetaminas, uma ampla classe de substâncias presentes em drogas de abuso como ecstasy ou em fármacos como os anorexígenos, respondem pelo segundo maior grupo de usuários de drogas, seguido dos usuários de cocaína e opioides, respectivamente. ${ }^{10}$

Esta revisão busca divulgar, em âmbito nacional, informações sobre a ocorrência de drogas de abuso em águas naturais e residuárias. Também será apresentado o estado da arte sobre as abordagens metodológicas empregadas para o preparo de amostras de diferentes procedências, bem como as principais técnicas utilizadas para a determinação dessas substâncias, buscando tornar evidente a importância dos estudos recentes voltados à investigação desta classe de contaminantes emergentes ainda pouco estudada.

\section{CLASSIFICAÇÃO E PRODUTOS DE METABOLIZAÇÃO}

No Brasil, definições legais sobre drogas de abuso estão publicadas na Portaria 344/98-SVS e suas atualizações, ${ }^{11}$ que definem quais substâncias e medicamentos são proscritos e quais estão sujeitos a mecanismos de controle especial relacionados a notificações, licenças, autorizações e prescrições médicas. O termo drogas ilícitas refere-se, portanto, àquelas drogas ou substâncias usadas de forma abusiva, isto é, fora de contexto médico ou legal e que, segundo a Portaria em questão, são de uso proscrito ou proibido no Brasil. Além disso, por serem legalmente consideradas substâncias capazes de causar dependência, ${ }^{12}$ sua produção, comercialização e consumo sob condições não previstas são tipificados como crimes, sendo os responsáveis sujeitos a processos penais cujas penas chegam a 20 anos de reclusão.

As drogas de abuso abrangem uma grande variedade de substâncias químicas. Entretanto, uma das abordagens empregadas para a classificação destas substâncias busca ordená-las em quatro grupos 
distintos. Segundo o Relatório Anual do Observatório Europeu das Drogas e da Toxicodependência ${ }^{13}$ (European Monitoring Centre of Drugs and Drug Addiction), as drogas de abuso podem ser divididas em canabinoides, estimulantes anfetamínicos e outras substâncias alucinógenas, cocaínicos e opioides.

A Figura 1 apresenta a estrutura química das substâncias químicas derivadas das drogas de abuso mais investigadas em estudos ambientais, assim como de alguns metabólitos gerados a partir do consumo de tais substâncias.

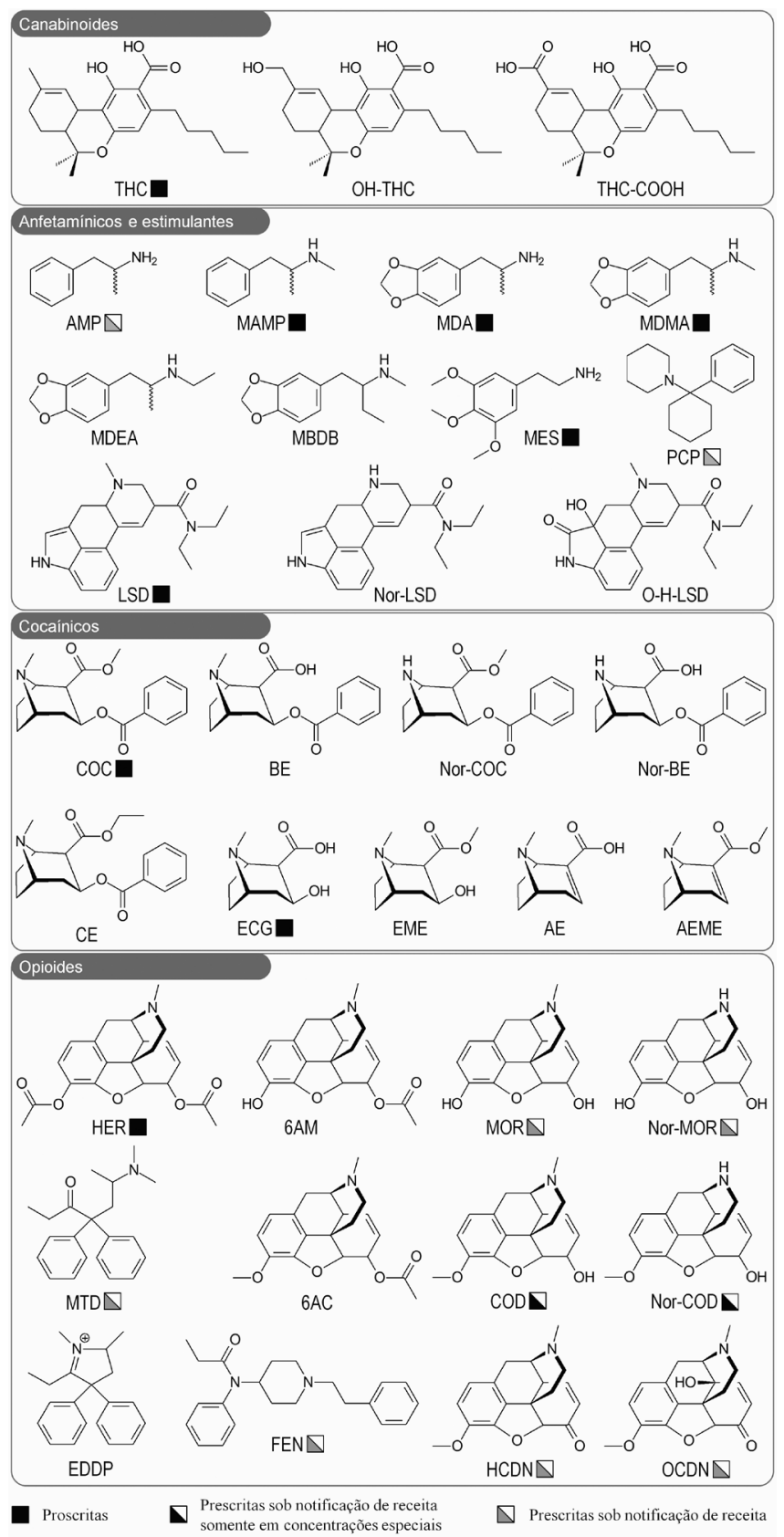

Figura 1. Estruturas químicas das principais drogas de abuso e de seus metabólitos investigados em águas naturais e residuárias urbanas e mecanismos de controle segundo Portaria 344/98-SVS

\section{Canabinoides}

Este grupo compreende os produtos obtidos a partir da planta de maconha ou cannabis. Segundo o Glossário de Álcool e Drogas, ${ }^{14}$ existem, pelo menos, 60 tipos de canabinoides conhecidos, sendo a maioria biologicamente ativa. O delta-9-tetra-hidrocanabinol, mais conhecido como tetra-hidrocanabinol (THC), é o principal componente ativo desse grupo. Depois de metabolizado, o THC é principalmente excretado pela urina como 11-nor-9-carboxi-delta-9-tetra-hidrocanabinol (carbóxi-THC ou THC-COOH). ${ }^{15}$ Outro metabólito frequentemente estudado é o 11-hidroxi-delta-9-tetra-hidrocanabinol (OH-THC) em função de ser considerado mais ativo que o $\mathrm{THC}-\mathrm{COOH}$

\section{Cocaínicos}

A cocaína é o principal representante deste grupo. Pertencente à classe dos alcaloides tropânicos, a cocaína (COC) é obtida majoritariamente a partir das folhas de coca (Erythroxylum coca) ou, mais raramente, sintetizada a partir da ecgonina (ECG) e derivados. ${ }^{14} \mathrm{Em}$ seres humanos apenas uma pequena fração da COC consumida é excretada na urina e nas fezes sem ser metabolizada. ${ }^{13,16}$ A maior parcela é excretada sob a forma de metabólitos, sendo o principal deles a benzoilecgonina (BE). ${ }^{5}$ Outros metabólitos incluem o metil-éster da ecgonina (EME) e o cocaetileno (CE), substância esta formada no fígado a partir da metabolização da COC quando consumida juntamente com bebidas alcoólicas. As formas de administração da COC são diversas, como inalação, uso intravenoso ou ingestão. Além destas, a COC também pode ser fumada, como quando consumida sob a forma de apresentação conhecida como crack. Neste caso, em função dos processos de vaporização da droga sob temperaturas elevadas, outros metabólitos também são excretados, tais como a anidroecgonina (AE) e o metil-éster da anidroecgonina (AEME). Outros metabólitos relevantes da COC são a norcocaína (Nor-COC) e a norbenzoilecgonina (Nor-BE).

\section{Opioides}

Os opioides incluem drogas que atuam em receptores celulares neuronais e específicos denominados receptores opioides. Dentro deste grupo, os opiáceos incluem as substâncias naturais derivadas do ópio - um extrato vegetal obtido a partir das flores da papoula (Papaver somniferum) e cujo principal alcaloide presente é a morfina. ${ }^{10}$

Alguns opioides possuem grande aplicabilidade em medicina dada a capacidade de aliviar dores de diversas naturezas. Porém, o consumo dessas substâncias como drogas de abuso tem sido relatado desde a década de $1970 .{ }^{13}$ Os opioides mais frequentemente estudados no ambiente são morfina (MOR), normorfina (Nor-MOR), codeína (COD), norcodeína (Nor-COD), hidrocodona (HCDN), oxicodona (OCDN), metadona (MTD) e fentanila (FEN). Todas estas substâncias têm seu uso controlado no Brasil. ${ }^{11}$ A heroína (HER), ou diacetilmorfina, é o único opioide proscrito no Brasil. Quando ingeridas ou administradas, algumas substâncias deste grupo geram uma série de metabólitos que também são analitos de interesse ambiental. Neste sentido, muitos estudos buscam investigar a ocorrência da 6-acetilmorfina (6AM) e da 6-acetilcodeína (6AC), metabólitos da heroína e da codeína, respectivamente, além da presença do 2-etilideno-1,5-dimetil-3,3-difenilpirrolidina (EDDP), principal metabólito da MTD, uma droga opioide muito utilizada no tratamento de dependentes de heroína.

\section{Estimulantes anfetamínicos e outras substâncias alucinógenas}

Os estimulantes anfetamínicos, Amphetamine-Type Stimulants (ATS), compreendem substâncias sintéticas da família alfa-metilfenil-aminas que inclui a própria anfetamina (AMP), a metanfetamina (MAMP) e derivados do grupo do ecstasy, representados pelas 
substâncias 3,4-metilenodioxianfetamina (MDA), 3,4-metilenodioximetanfetamina (MDMA), 3,4-metilenodioxietilanfetamina (MDEA), metilbenzodioxolilbutanamina (MBDB), entre outras. ${ }^{10}$ Ainda, dentre as substâncias sintéticas alucinógenas frequentemente estudadas deste grupo estão a fenciclidina (PCP) e a dietilamida do ácido lisérgico ou, como é popularmente conhecida, LSD. Todas as substâncias deste amplo grupo agem no sistema nervoso central e, diferentemente da COC, do THC e dos opioides, são excretadas inalteradas, ou seja, tais como foram consumidas. ${ }^{15}$ Exceção é feita em estudos envolvendo o LSD, nos quais é também investigada a ocorrência de dois metabólitos gerados a partir do consumo da droga, ou seja, o Nor-LSD e o 2-oxo-3-hidroxi-LSD (O-H-LSD). ${ }^{17-19}$ A mescalina (MES), um dos poucos alucinógenos naturais deste grupo, também vem sendo recentemente estudada. ${ }^{19}$

\section{PROPRIEDADES DE INTERESSE AMBIENTAL}

Propriedades como solubilidade em água, coeficiente de partição octanol/água $\left(\mathrm{K}_{\mathrm{ow}}\right)$, pressão de vapor, entre outras, ${ }^{20}$ podem ser empregadas para prever aspectos relacionados ao transporte, persistência e destino de substâncias químicas no ambiente. Informações deste tipo sobre drogas de abuso ainda são escassas, principalmente no que tange às propriedades relevantes à compreensão dos riscos associados à exposição ambiental de humanos e outros seres vivos a estas substâncias. ${ }^{6-8} \mathrm{~A}$ Tabela 1 apresenta alguns destes parâmetros para drogas de abuso e seus metabólitos.

Tabela 1. Número CAS e propriedades físico-químicas de algumas drogas de abuso e seus metabólitos

\begin{tabular}{|c|c|c|c|c|}
\hline Substância & Número CAS & $\mathrm{pK}_{\mathrm{a}}$ & $\begin{array}{c}\text { Pressão de } \\
\text { vapor }(\mathrm{mmHg} \text {, } \\
\left.25^{\circ} \mathrm{C}\right)\end{array}$ & $\log \mathrm{K}_{\mathrm{ow}}$ \\
\hline \multicolumn{5}{|c|}{ Canabinoides } \\
\hline THC & $1972-08-3$ & 10,6 & $1,18 \times 10^{-6}$ & 7,68 \\
\hline THC-COOH & 56354-06-4 & 3,0 & n.d. & 6,14 \\
\hline \multicolumn{5}{|c|}{ Cocaínicos } \\
\hline $\mathrm{COC}$ & $50-36-2$ & 8,6 & $1,91 \times 10^{-7}$ & 3,08 \\
\hline $\mathrm{BE}$ & $519-09-5$ & $\begin{array}{l}3,2\left(\mathrm{pK}_{\mathrm{a} 1}\right) \\
10,1\left(\mathrm{pK}_{\mathrm{a} 2}\right)\end{array}$ & n.d. & 2,72 \\
\hline EME & 7143-09-1 & $\begin{array}{l}9,3\left(\mathrm{pK}_{\mathrm{a} 1}\right) \\
14,2\left(\mathrm{pK}_{\mathrm{a} 2}\right)\end{array}$ & n.d. & $-0,23$ \\
\hline \multicolumn{5}{|c|}{ Opioides } \\
\hline HER & $561-27-3$ & 7,6 & $7,58 \times 10^{-10}$ & 1,52 \\
\hline MOR & $57-27-2$ & $7,9-9,4$ & n.d. & 0,76 \\
\hline $6 \mathrm{AM}$ & $2784-73-8$ & $\begin{array}{l}8,19\left(\mathrm{pK}_{\mathrm{a} 1}\right) ; \\
9,55\left(\mathrm{pK}_{\mathrm{a} 2}\right)\end{array}$ & n.d. & 0,42 \\
\hline COD & $76-57-3$ & 8,2 & n.d. & 1,20 \\
\hline MTD & 76-99-3 & 9,2 & n.d. & 1,49 \\
\hline \multicolumn{5}{|c|}{ Estimulantes anfetamínicos e outras substâncias alucinógenas } \\
\hline AMP & $300-62-9$ & 10,1 & 0,307 & 1,81 \\
\hline MAMP & $537-46-2$ & 9,9 & 0,147 & 2,07 \\
\hline MDA & $4764-17-4$ & 10,0 & n.d. & 1,59 \\
\hline MDMA & $42542-10-9$ & 10,4 & 0,003 & 1,81 \\
\hline LSD & $82-58-6$ & 7,8 & $9,00 \times 10^{-10}$ & 2,71 \\
\hline
\end{tabular}

Em estudos ambientais, a distribuição de uma substância química em equilíbrio entre a água e o octanol $\left(\mathrm{K}_{\mathrm{ow}}\right)$ relaciona-se com o grau de hidrofobicidade da substância. ${ }^{21}$ Valores elevados de $\log \mathrm{K}_{\mathrm{ow}}$ indicam tendência do composto em acumular-se em meios hidrofóbicos, como solos, sedimentos, material particulado e biota. Por essa razão, este parâmetro é frequentemente utilizado para estimar o fator de bioconcentração (FBC) de substâncias químicas, ${ }^{21,22}$ prevendo o acúmulo de uma dada substância no tecido adiposo de peixes quando o mecanismo de difusão é a única via de exposição. Em geral, substâncias que apresentam valores de $\log \mathrm{K}_{\mathrm{ow}}$ superiores a 7 são capazes de interagir com a matéria orgânica de sedimentos, o que torna "improvável que adquiram mobilidade suficiente para introduzir-se nos tecidos vivos". ${ }^{21}$ É possível observar, na Tabela 1, que os canabinoides podem ser considerados, sob esta ótica, hidrofóbicos ao ponto de se acumularem na matéria orgânica e/ou exibirem algum grau de bioconcentração em sistemas biológicos. Entretanto, convém mencionar que mecanismos específicos de absorção e metabolização destas substâncias pela biota, ainda pouco estudados, irão definir o verdadeiro efeito de drogas de abuso no ambiente.

A constante de dissociação ácida $\left(\mathrm{pK}_{\mathrm{a}}\right)$ indica o caráter ácido ou básico da substância em meio aquoso, ou mais especificamente, se a mesma está dissociada ou não. Nota-se, com base nos valores da Tabela 1, que BE e THC-COOH exibem caráter ácido. Assim, considerando que o $\mathrm{pH}$ de águas naturais e residuárias geralmente está entre 4 e $9,{ }^{23}$ é possível prever se tais substâncias se encontram majoritariamente sob suas formas protonadas ou desprotonadas em ambientes aquáticos.

A volatilidade de uma substância também é importante na compreensão do seu comportamento no ambiente. No entanto, a volatilização de substâncias químicas da superfície da água para a atmosfera é mais bem avaliada a partir das constantes da Lei de Henry $\left(\mathrm{K}_{\mathrm{H}}\right)$. Em geral, valores de $\mathrm{K}_{\mathrm{H}}$ podem ser estimados pela razão entre a pressão de vapor da substância e sua solubilidade. ${ }^{24}$

Domènech e colaboradore ${ }^{25}$ propuseram um modelo de fugacidade com base em diversos parâmetros, entre eles $\mathrm{K}_{\mathrm{H}}$ e $\mathrm{pK}_{\mathrm{a}}$, para prever o comportamento e distribuição de COC e BE entre compartimentos ambientais como ar, água, solo, sedimentos e material suspenso. Este tipo de ferramenta já tem sido empregado como suporte no desenvolvimento de sistemas regulatórios e de controle de produtos químicos por órgãos de regulação como a Agência de Proteção Ambiental dos Estados Unidos (U.S.EPA).

Em alguns casos, uma mesma droga de abuso pode ser encontrada sob diferentes formas de apresentação a depender da maneira como é consumida. O exemplo mais representativo é o da COC que pode ser fumada na forma de pasta base ou crack, ou ser inalada na forma de cloridrato de cocaína. A COC, sob a primeira forma de administração, é considerada neutra e insolúvel em água, enquanto que o sal de cloridrato possui elevada solubilidade em meio aquoso.

\section{FONTES E DISTRIBUIÇÃO NO AMBIENTE}

A presença de drogas de abuso no ambiente tem sido confirmada desde o final do século XX, quando Hannigan e colaboradores ${ }^{26}$ verificaram a existência de COC em níveis mensuráveis no ar de Los Angeles (EUA). Porém, somente no início deste século, estudos sobre a ocorrência destas drogas no ambiente, principalmente em águas naturais e residuárias urbanas, tornaram-se frequentes.

Inúmeras atividades contribuem para o aporte de substâncias químicas no ambiente. Entretanto, o descarte de esgoto bruto e de efluentes de estações de tratamento de esgoto (ETE) são consideradas fontes majoritárias de aporte de inúmeros contaminantes emergentes para sistemas aquáticos, ${ }^{27}$ incluindo as drogas de abuso. A Figura 2 mostra as principais vias de transporte de drogas de abuso, assim como de seus metabólitos, para o ambiente.

A rota 1 representa o enriquecimento do esgoto bruto com drogas de abuso a partir da excreção fecal e/ou urinária de usuários, além da contribuição do descarte intencional e/ou acidental de drogas em sistemas de captação de esgotos. Os serviços de esgotamento sanitário são representados pelas rotas 2 e 3 , sendo que a primeira corresponde 


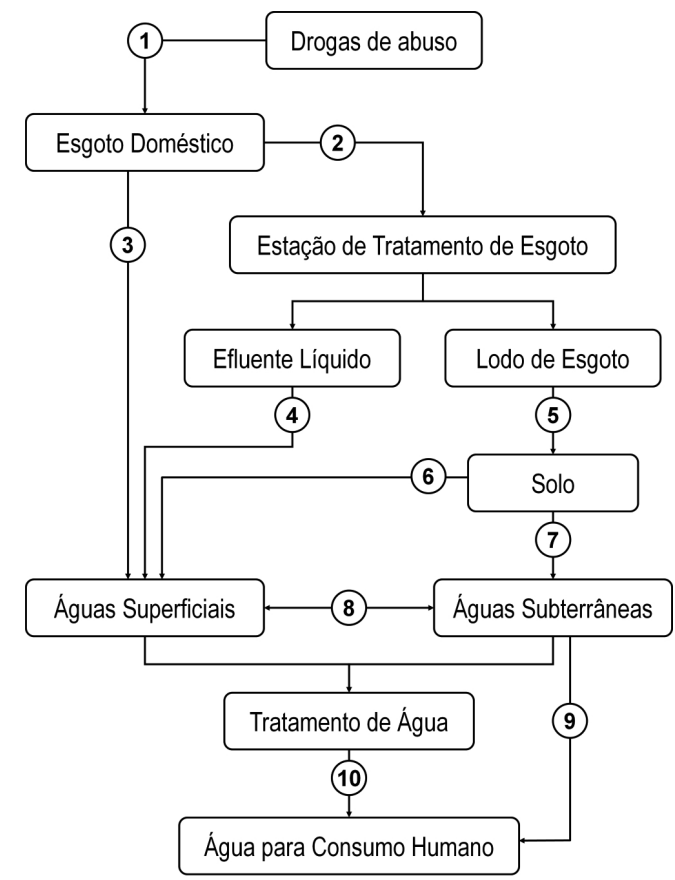

Figura 2. Origem e destino de drogas de abuso no ambiente

à canalização do esgoto até as ETE e a segunda, ao serviço de afastamento do esgoto bruto da população. $\mathrm{O}$ descarte clandestino do esgoto também é contemplado na rota 3.

Em ETE convencionais, os métodos de tratamento não foram projetados para a eliminação de muitos contaminantes emergentes, como as drogas de abuso. Consequentemente, o lançamento de efluentes de ETE em águas é uma das principais fontes de contaminação do ambiente por esse grupo de substâncias. Mesmo assim, os diversos processos existentes durante o tratamento são, eventualmente, capazes de degradar, fixar, remover ou biotransformar tais substâncias. A remoção de drogas ilícitas após tratamento biológico e/ou com lodo ativado foi investigada em 8 ETE localizadas na Espanha. ${ }^{6}$ Neste estudo, as porcentagens máximas de remoção para AMP e MAMP foram bastante elevadas (>99\%), mas a remoção mínima foi de 52 e $44 \%$, respectivamente. Já para COC e BE, todas as ETE investigadas apresentaram percentuais de remoção maiores que $88 \%$. Mesmo assim, concentrações relativamente elevadas de tais substâncias ainda foram observadas nos efluentes de algumas das estações investigadas, refletindo as concentrações elevadas no esgoto bruto.

Assim como em ambientes aquáticos naturais, nas ETE é possível prever ou estimar a fugacidade de uma substância química, ou seja, sua permanência no efluente líquido ou no lodo gerado durante o tratamento. Obviamente que, durante o processo de tratamento, muitas substâncias podem ser total ou parcialmente degradadas ou biotransformadas. Mesmo assim, o conhecimento de algumas propriedades físico-químicas (Tabela 1), pode subsidiar ações ou direcionar estudos voltados ao diagnóstico de áreas ou ambientes aquáticos impactados pela ocorrência de drogas de abuso. Este conhecimento é notadamente importante uma vez que o efluente líquido é geralmente descartado em sistemas de águas superficiais, conforme aponta a rota 4 da Figura 2, enquanto que o material sólido pode ser utilizado para fertilização e/ ou condicionamento de solos agricultáveis (rota 5). Assim, a contaminação de águas naturais por meio do escoamento superficial (rota 6) ou da lixiviação (rota 7) também pode ocorrer caso drogas de abuso estejam presentes no lodo de esgoto aplicado ao solo.

A rota 8, mostrada na Figura 2, representa a interface existente entre os sistemas aquáticos superficiais e subterrâneos. A água subterrânea pode ser bombeada e utilizada para fins de consumo (rota 9) ou submetida a tratamento. Finalmente, a rota 10 representa a distribuição de água para consumo humano por meio de redes municipais de distribuição ou caminhões-pipa.

Águas superficiais são captadas e canalizadas para estações de tratamento de águas (ETA). Assim como nas ETE, os processos convencionais de tratamento nas ETA não são eficientes para a eliminação de drogas de abuso. Huerta-Fontela e colaboradore ${ }^{28}$ monitoraram a presença de drogas de abuso nas etapas de tratamento de água em algumas ETA da Espanha. Todos os estimulantes anfetamínicos, com exceção do MDMA, foram removidos durante as etapas de floculação e filtração. Para COC, MDMA e BE foi observada uma remoção de 100,88 e $72 \%$, respectivamente, após etapa de filtração com carvão ativado. Ao final de todas as etapas do tratamento, resíduos de BE ainda foram detectados na água tratada.

\section{OCORRÊNCIA EM ÁGUAS NATURAIS E RESIDUÁRIAS}

O interesse com relação à ocorrência de drogas de abuso em ambientes aquáticos surge em função de dois aspectos distintos: o conhecimento das concentrações destes contaminantes emergentes no ambiente, uma vez que podem apresentar algum grau de toxicidade e, a possibilidade de utilizar as informações obtidas como indicadores de interesse para as áreas forense e de segurança e saúde públicas.

Em 2004, Jones-Leep e colaboradores, ${ }^{4}$ em trabalho pioneiro, determinaram drogas de abuso em amostras aquosas de interesse ambiental. Na ocasião, foi detectada a presença de MAMP e MDMA no efluente de 3 ETE dos Estados Unidos. No ano seguinte, Zuccato e colaboradores ${ }^{5}$ apresentaram um estudo direcionado à presença de COC e BE em amostras de águas superficiais e de esgoto bruto. As concentrações de COC e BE determinadas em amostras do Rio Pó, na Itália, foram de 1,2 e $25 \mathrm{ng} \mathrm{L}^{-1}$, respectivamente, enquanto que no esgoto bruto coletado em 4 ETE as concentrações variaram entre 42 e $120 \mathrm{ng} \mathrm{L}^{-1}$ para COC e entre 420 e $750 \mathrm{ng} \mathrm{L}^{-1}$ para BE.

Desde então, a ocorrência de drogas de abuso de diferentes classes, assim como muitos metabólitos, tem sido investigada tanto em ambientes aquáticos naturais quanto em amostras provenientes de sistemas de tratamento de esgoto. Um levantamento realizado na plataforma SCOPUS ${ }^{29}$ em agosto de 2012 revelou que, desde 2004, o número de publicações sobre o tema tem crescido de maneira exponencial. A vasta maioria dos trabalhos tem sido realizada na Europa, sendo a Espanha o país que mais tem gerado informações sobre a ocorrência de drogas de abuso em amostras de interesse ambiental, respondendo por mais de $20 \%$ dos trabalhos gerados entre 2004 e 2012. A Figura 3 mostra as concentrações máximas de COC e BE observadas em amostras de água superficial e de esgoto de diferentes países desde 2004.

Dentre as substâncias da classe dos cocaínicos, COC e BE têm sido as mais investigadas em função do elevado padrão de consumo global de cocaína. Dentre todos os trabalhos publicados sobre a ocorrência de drogas de abuso em águas naturais e/ou residuárias, cerca de $90 \%$ envolvem a determinação de BE, enquanto que $85 \%$ dos trabalhos buscam determinar os níveis de COC nas amostras. Também são alvos de investigação CE (30\%), EME (16\%), Nor-BE (14\%), Nor-COC (13\%) e ECG (5\%). Além dos metabólitos mencionados, cabe citar o número crescente de publicações envolvendo substâncias provenientes de processos térmicos de desidratação da cocaína, AE e AEME, que foram estudados em 4 e $7 \%$ dos trabalhos publicados até 2012, respectivamente, e podem indicar a utilização significativa da cocaína na forma fumada como crack, por exemplo.

Ainda na Figura 3, observam-se níveis de concentração variando entre 2 e 3 ordens de magnitude para cada tipo de matriz investigada, ou seja, na faixa entre $\mu \mathrm{g} \mathrm{L}^{-1}$ e ng L ${ }^{-1}$. Nota-se também uma diminuição gradual de concentração quando as amostras são avaliadas no 


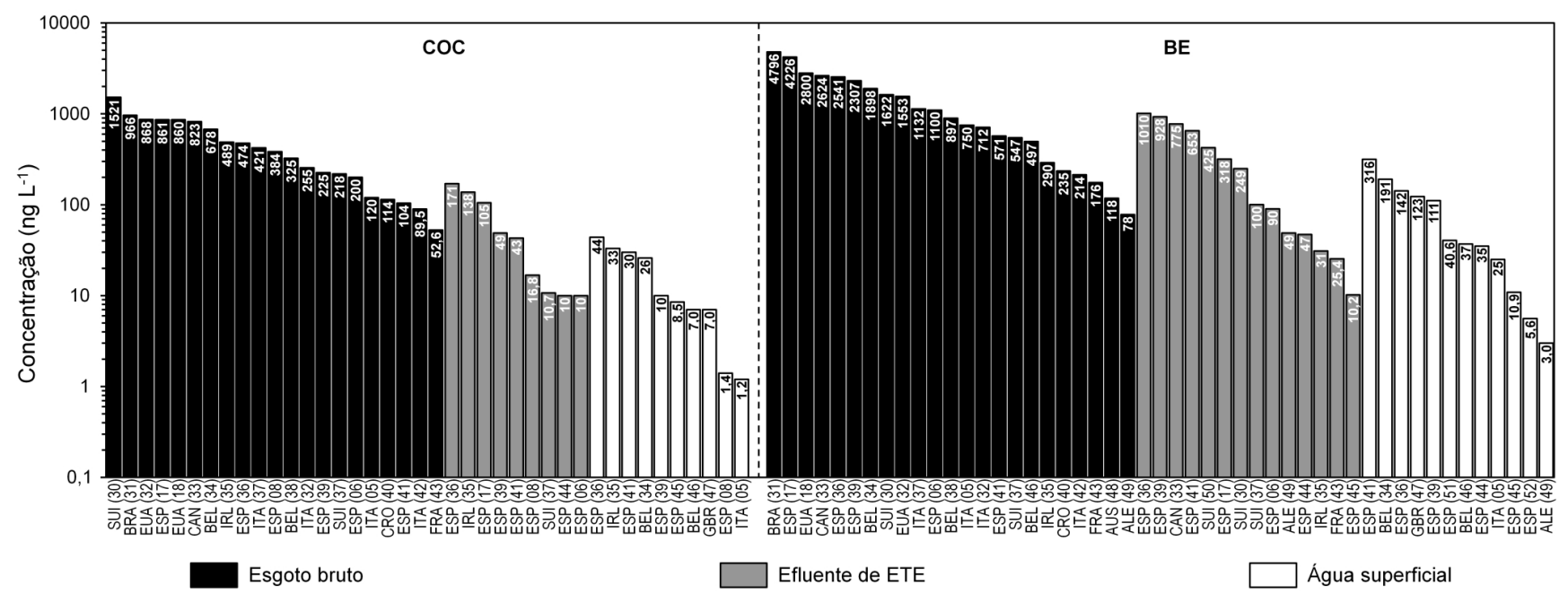

Figura 3. Concentração máxima de cocaína (COC) e benzoilecgonina (BE) em amostras de esgoto bruto (em preto), esgoto tratado (em cinza) e águas superficiais (em branco) obtidas em diferentes trabalhos. Valores individuais são mostrados no topo de cada coluna e as respectivas referências são indicadas entre parênteses ao lado do país onde o estudo foi realizado

sentido esgoto bruto $\rightarrow$ água superficial. Este comportamento tem sido comum em estudos sobre contaminantes emergentes no ambiente, evidenciando o papel do esgoto bruto como fonte majoritária de contaminação de águas. ${ }^{27}$ As concentrações nos efluentes de ETE são superiores às encontradas em águas superficiais em função de fenômenos como diluição, biodegradação, fotodegradação, adsorção, além de alterações dinâmicas da vazão, mistura e turbulências das águas superficiais.

Tanto a faixa de concentração quanto o comportamento de COC e BE no sentido esgoto bruto $\rightarrow$ água superficial são similares aos observados para as demais drogas de abuso investigadas no ambiente, como mostram as Figuras 4 e 5.

As concentrações máximas de alguns representantes do grupo dos estimulantes anfetamínicos e de outras substâncias alucinógenas são mostradas na Figura 4. Embora MAMP e MDMA tenham sido as primeiras drogas de abuso determinadas em amostras aquosas de interesse ambiental, a AMP tem sido a substância mais frequentemente investigada, uma vez que cerca de $62 \%$ das publicações a incluem como substância-alvo. MAMP e MDMA também têm sido extensivamente estudadas (57 e 55\% das vezes, respectivamente), assim como MDA (25\%) e MDEA (20\%). O LSD tem sido investigado em $18 \%$ dos trabalhos publicados sobre o tema, embora seus produtos de metabolização Nor-LSD (7\%) e O-H-LSD (12\%) também sejam frequentemente incluídos como substâncias-alvo. Além das drogas de abuso mencionadas, outras substâncias anfetamínicas e/ou alucinógenas como PCP, MBDB, efedrina, benzopiridina e catinona também vêm sendo investigadas em amostras ambientais, porém de maneira menos extensiva.

Os opioides mais frequentemente estudados em matrizes de águas naturais e residuárias são mostrados na Figura 5. A morfina e o principal produto de metabolização da heroína, a 6AM, são os compostos mais investigados desta classe e são incluídos como substâncias de interesse em 43 e $38 \%$ das publicações sobre o tema, respectivamente. Em seguida, as substâncias mais frequentemente investigadas deste grupo são a MTD (31\%) e seu metabólito EDDP (29\%). Embora a HER seja o único opioide proscrito, sua fácil metabolização acarreta que apenas $18 \%$ das publicações buscam investigar sua ocorrência. A COD tem sido investigada em $27 \%$ das

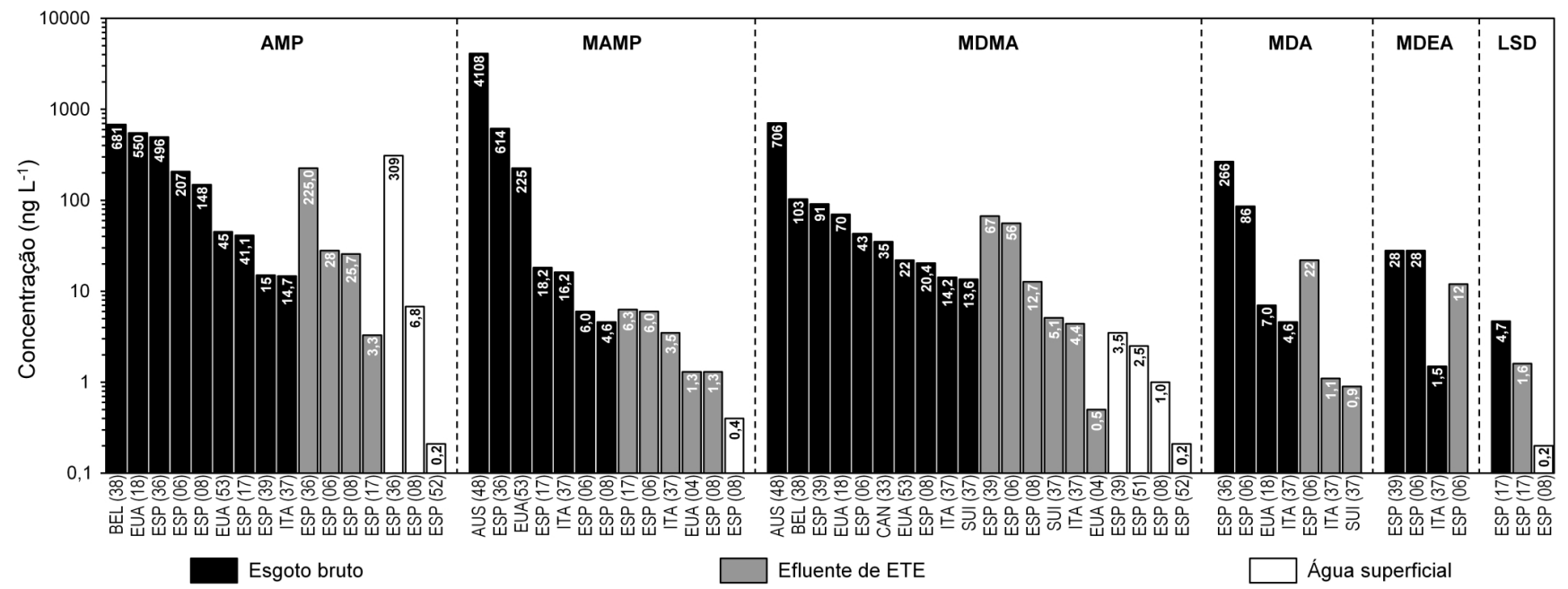

Figura 4. Concentração máxima de anfetamina (AMP), metanfetamina (MAMP), LSD e de compostos do grupo do ecstasy (MDMA, MDA e MDEA) em amostras de esgoto bruto (em preto), esgoto tratado (em cinza) e águas superficiais (em branco) obtidas em diferentes trabalhos. Valores individuais são mostrados no topo de cada coluna e as respectivas referências são indicadas entre parênteses ao lado do país onde o estudo foi realizado 


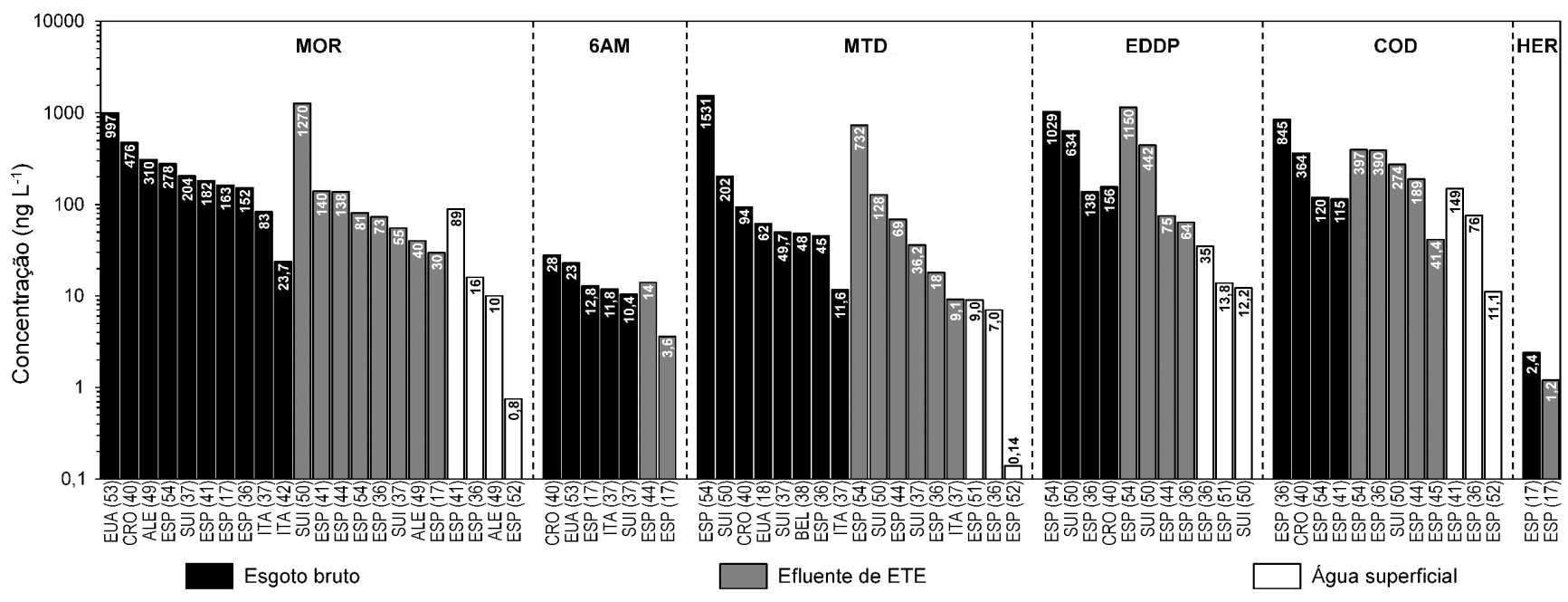

Figura 5. Concentração máxima de heroína (HER), codeína (COD), morfina (MOR), metadona (MTD) e dos metabólitos EDDP e 6-acetilmorfina em amostras de esgoto bruto (em preto), esgoto tratado (em cinza) e águas superficiais (em branco) obtidas em diferentes trabalhos. Valores individuais são mostrados no topo de cada coluna e as respectivas referências são indicadas entre parênteses ao lado do país onde o estudo foi realizado

publicações, enquanto que as drogas $\mathrm{HCDN}$ e OCDN, derivadas da COD e da tebaína, já foram incluídas como substâncias-alvo em 7 e 9\% dos trabalhos publicados sobre o tema, respectivamente. Outras substâncias do grupo dos opioides têm sido incluídas de maneira intermitente em investigações ambientais, tais como Nor-COD, Nor-MOR, 6AC, morfina-glucuronídeo, fentanil, buprenorfina, tramadol e propoxifeno.

De maneira geral, as substâncias do grupo dos canabinoides têm sido as menos estudadas em matrizes de águas naturais e residuárias. A Figura 6 mostra os níveis de concentração máximos de THC, THC$\mathrm{COOH}$ e OH-THC observados em estudos ambientais. Considerandose que o THC é prontamente metabolizado após administração, a maior parte dos estudos voltados à ocorrência de drogas de abuso em águas, ou seja, cerca de $30 \%$, busca investigar o THC-COOH. Em seguida, aparecem o próprio THC (16\%) e o OH-THC (10\%). Outras substâncias deste grupo eventualmente investigadas são o canabinol e o canabidiol.

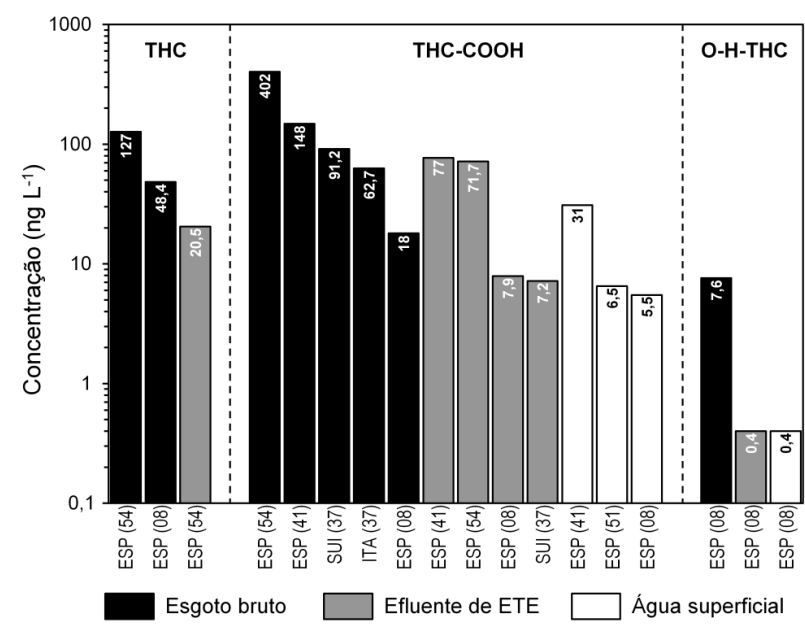

Figura 6. Concentração máxima de tetra-hidrocanabinol (THC) e de seus metabólitos THC-COOH e OH-THC em amostras de esgoto bruto (em preto), esgoto tratado (em cinza) e águas superficiais (em branco) obtidas em diferentes trabalhos. Valores individuais são mostrados no topo de cada coluna e as respectivas referências são indicadas entre parênteses ao lado do país onde o estudo foi realizado

\section{OCORRÊNCIA EM OUTRAS MATRIZES}

A ocorrência de drogas de abuso também tem sido confirmada no material particulado atmosférico, ${ }^{26,55-57}$ no material particulado de águas residuárias, ${ }^{19,33} \mathrm{em}$ amostras de lodo de esgoto e sedimentos de ETE, ${ }^{58-60} \mathrm{em}$ águas subterrâneas ${ }^{61} \mathrm{e}$ na água para consumo humano. ${ }^{62}$

Cecinato e Balducci ${ }^{55}$ encontraram concentrações de COC entre 10 e 98 pg m$^{-3}$ em amostras atmosféricas de Roma e Taranto (Itália). Viana e colaboradores ${ }^{56}$ determinaram a presença de COC, BE, CE, cinco anfetamínicos, três opioides e três canabinoides no material particulado atmosférico de três cidades da Espanha. A média diária dos analitos nas partículas do ar ficou entre 11 e $336 \mathrm{pg} \mathrm{m}^{-3}$ para COC, entre 23 e $34 \mathrm{pg} \mathrm{m}^{-3}$ para os canabinoides e entre 5 e $90 \mathrm{pg} \mathrm{m}^{-3}$ para HER.

O primeiro estudo sobre a ocorrência de drogas de abuso em águas subterrâneas foi realizado na cidade de Barcelona (Espanha) ${ }^{61}$ Dentre 21 substâncias alvo, 5 foram encontradas em mais de $30 \%$ das amostras analisadas. As concentrações mais elevadas foram determinadas para MTD $\left(68,3 \mathrm{ng} \mathrm{L}^{-1}\right)$ e COC $\left(60,2 \mathrm{ng} \mathrm{L}^{-1}\right)$.

A presença de drogas de abuso em amostras de água para consumo humano foi investigada de maneira bastante detalhada por Boleda e colaboradores. ${ }^{62}$ Nesse estudo, 70 amostras de 16 países europeus, do Japão e de 9 países da América Latina, incluindo o Brasil, foram investigadas. Os resultados revelaram concentrações médias abaixo de $1 \mathrm{ng} \mathrm{L}^{-1}$ para as drogas de abuso investigadas, sendo que nas amostras provenientes na América Latina foram determinadas as maiores concentrações médias de COC e BE, ou seja, 0,6 e 4,5 ng L ${ }^{-1}$, respectivamente.

\section{ESTIMANDO O CONSUMO DE DROGAS}

Christian G. Daughton, pesquisador da U.S.EPA, propôs, em 2001, que seria possível estimar o consumo de drogas de abuso por uma população a partir de algumas informações, tais como a concentração dos resíduos destas substâncias no esgoto bruto, o metabolismo da droga no organismo, o percentual de excreção de cada metabólito e/ou da droga inalterada, a vazão de entrada de esgoto nas ETE e o número de pessoas atendidas pela ETE investigada. ${ }^{63}$ Caracterizada pela rapidez e objetividade na obtenção de informações sobre a quantidade de drogas de abuso consumida e tendências de consumo, esta nova abordagem, denominada pela comunidade científica como 
"epidemiologia do esgoto" ou "epidemiologia forense", tem sido apresentada como uma alternativa ao monitoramento do consumo e do tráfico de drogas e, igualmente, aos mecanismos tradicionais de identificação do perfil de usuários, ${ }^{64,65}$ apresentando-se como mais uma ferramenta no enfrentamento às drogas.

Uma vez no esgoto, a ocorrência da droga inalterada ou de um ou mais metabólitos pode ser determinada por meio do estabelecimento de etapas de amostragem, preservação e preparo da amostra que culminam com a extração do composto de interesse e com sua identificação e/ou quantificação por meio de técnicas avançadas de separação e detecção analítica. ${ }^{5,65-67}$ Estas etapas, detalhadas ao longo desta revisão, representam o maior desafio sob o ponto de vista químico na determinação de drogas de abuso em matrizes aquosas complexas como águas naturais e residuárias urbanas. A estimativa do consumo baseia-se na realização de um retrocálculo, que leva em consideração a concentração da droga ou do metabólito no esgoto, além de uma série de informações complementares. A Equação 1 mostra que a estimativa de consumo $\left(C\right.$, em mg hab ${ }^{-1}$ dia $\left.^{-1}\right)$ pode ser obtida com base na concentração da substância alvo no esgoto $\left(c\right.$, em $\left.\mathrm{mg} \mathrm{L}^{-1}\right)$, na vazão volumétrica do esgoto que aflui na ETE (, em L dia ${ }^{-1}$ ), em um fator de correção $(f)$ relativo à proporção da droga metabolizada e excretada após o uso e no número de habitantes $(h a b)$ atendidos pela ETE.

$$
C=\frac{c \times Q_{V} \times f}{h a b}
$$

No primeiro trabalho a colocar em prática a epidemiologia do esgoto, em 2005, Zuccato e colaboradores ${ }^{5}$ determinaram a quantidade $\mathrm{COC}$ e $\mathrm{BE}$ em amostras de esgoto bruto. A quantidade de COC consumida foi estimada multiplicando a massa de BE encontrada no esgoto por um fator relativo à proporção da $\mathrm{COC}$ metabolizada à $\mathrm{BE}$. De acordo com os autores, o consumo de COC obtido empiricamente $\left(0,44 \mathrm{mg} \mathrm{hab}^{-1} \mathrm{dia}^{-1}\right)$ foi consideravelmente superior àquele relatado em dados oficiais.

Três anos depois, Huerta-Fontela e colaboradores ${ }^{6}$ utilizaram aproximações semelhantes às realizadas pelo grupo de Zuccato para estimar, com base em amostras de esgoto de 42 ETE da Espanha, o consumo de COC e MDMA. Os resultados apontaram um consumo médio de 3,3 e 0,4 mg hab ${ }^{-1} \mathrm{dia}^{-1}$ para COC e MDMA, respectivamente, considerando-se apenas usuários na faixa etária entre 15 e 34 anos.

Em publicação recente, van Nuijs e colaboradores ${ }^{68}$ avaliaram o consumo de COC, AMP, MDMA, MAMP, MTD e HER em Bruxelas (Bélgica) com base em resultados referentes a um ano de investigação. Diversas condições relacionadas ao cálculo da estimativa de consumo foram exploradas, dentre elas a estabilidade das substâncias no sistema de esgotamento sanitário, o número real de habitantes atendidos pelas ETE e a taxa de excreção do metabólito ou da droga inalterada. Os autores estimaram o consumo de COC, AMP, MDMA, MAMP, MTD e HER em 0,002; 0,138; 0,415; 0,519; 0,076 e 0,013 mg hab $\mathrm{dia}^{-1}$, respectivamente.

Postigo e colaboradores ${ }^{69}$ investigaram o consumo de drogas de abuso em um complexo penitenciário localizado na região da Catalunha (Espanha). O consumo médio diário de MTD, alprazolam, efedrina, maconha e COC foi estimado em 3,9; 0,129; 1,15;0,99 e 0,3 $\mathrm{mg} \mathrm{dia}^{-1} \mathrm{hab}^{-1}$, respectivamente. Também foi constatado um consumo esporádico de HER, AMP, MAMP e MDMA.

No Brasil, o consumo de COC foi estimado no Distrito Federal (DF) por meio da obtenção de amostras compostas de esgoto bruto provenientes de $6 \mathrm{ETE}$, que atendem juntas cerca de $70 \%$ da população do DF. ${ }^{31}$ Os resultados revelaram um consumo estimado de $1,08 \mathrm{mg} \mathrm{dia}^{-1} \mathrm{hab}^{-1}$.

Além das incertezas inerentes ao método analítico, estimativas obtidas pela epidemiologia do esgoto ainda se baseiam em condições e parâmetros pouco investigados. Mesmo já oferecendo respostas em tempo real, ou quasi-real, algumas incertezas envolvidas nos retrocálculos, tais como flutuações na população servida pela ETE, tempo de residência da droga no sistema de esgoto, estabilidade dos analitos, entre outras, ainda constituem desafios ao estabelecimento de resultados mais precisos através desta abordagem. ${ }^{13}$

Uma das principais discussões se baseia no estabelecimento das proporções das drogas metabolizadas e excretadas após o uso e que são adotadas nos retrocálculos. No caso da COC, por exemplo, a taxa de excreção assumida para BE, em muitos trabalhos, é de $45 \%$. 5,6,34,35 Contudo, esse valor representa uma média baseada em estudos realizados em laboratório, com quantidades relativamente pequenas de indivíduos e sob condições específicas. ${ }^{13}$ Assim, a incerteza sobre a porcentagem de excreção devido à influência de fatores como a forma de administração da COC (fumada, inalada ou injetada), quantidade consumida, sexo do usuário, entre outros, ainda é desconhecida. ${ }^{13,65}$ A Tabela 2 mostra fatores de correção originados a partir de informações referentes à proporção de metabolização/excreção de drogas de abuso.

Tabela 2. Drogas de abuso, substâncias-alvo, taxa de excreção e fatores de correção empregados em estudos de epidemiologia do esgoto

\begin{tabular}{ccccc}
\hline Droga & $\begin{array}{c}\text { Substância- } \\
\text { alvo }\end{array}$ & $\begin{array}{c}\text { Taxa de } \\
\text { excreção }(\%)\end{array}$ & $\begin{array}{c}\text { Razão molar } \\
\text { droga/ } \\
\text { substância- } \\
\text { alvo }\end{array}$ & $\begin{array}{c}\text { Fator de } \\
\text { correção }\end{array}$ \\
\hline COC & BE & $45^{\mathrm{b}}, 35^{\mathrm{c}}$ & 1,05 & $2,33^{\mathrm{b}} ; 3,0^{\mathrm{c}}$ \\
Maconha & THC-COOH & $15^{\mathrm{c}}$ & 1,52 & $10,13^{\mathrm{c}}$ \\
AMP & AMP & $30^{\mathrm{b}, \mathrm{c}}$ & 0,91 & $152^{\mathrm{b}}$ \\
MAMP & MAMP & $43^{\mathrm{b}, \mathrm{c}}$ & 1,0 & $3,33^{\mathrm{b}, \mathrm{c}}$ \\
Ectasy & MDMA & $65^{\mathrm{b}}, 20^{\mathrm{c}}$ & 1,0 & $2,33^{\mathrm{b}, \mathrm{c}}$ \\
HER & MOR & $42^{\mathrm{b}}$ & 1,29 & $3,54^{\mathrm{b}}, 5,0^{\mathrm{c}}$ \\
& $6 \mathrm{AM}$ & $1,3^{\mathrm{c}}$ & 1,13 & $86,92^{\mathrm{b}}$ \\
\hline
\end{tabular}

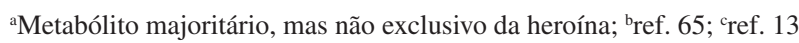

Além das propostas apresentadas por van Nuijs e colaboradores, ${ }^{68}$ algumas iniciativas para o refinamento dos retrocálculos incluem o uso de perfis individuais de excreção das substâncias-alvo de acordo com a via de administração da droga, ${ }^{70}$ a amostragem de esgoto por fluxo contínuo proporcional ${ }^{31}$ e métodos alternativos para identificação do número efetivo de habitantes atendidos pela ETE. ${ }^{71}$

Outro aspecto que também começa a ser explorado está relacionado ao perfil enantiomérico de algumas drogas de abuso encontradas no esgoto. ${ }^{72}$ Dentre as drogas que podem ser encontradas na forma opticamente ativa podem ser citadas COC, MAMP e AMP. ${ }^{73}$ Apesar dos isômeros ópticos apresentarem propriedades físico-químicas idênticas, o metabolismo e a excreção são diferentes por apresentarem interações específicas nos sistemas biológicos. ${ }^{72,74}$ Além disso, determinados isômeros ópticos dessas substâncias são empregados para fins terapêuticos e sua presença no esgoto não está ligada ao abuso de drogas ilícitas. Assim, traçar um perfil dos isômeros ópticos nos estudos de epidemiologia do esgoto pode auxiliar na distinção entre a procedência da droga (uso lícito ou ilícito), na verificação da via de administração e na identificação do método de síntese da droga de abuso. ${ }^{72,74}$

Diante das possibilidades mencionadas, a aplicação dessa abordagem à realidade brasileira apresenta perspectivas que vão além daquelas pensadas sob o ponto de vista dos estudos realizados em outros países. Devido ao grande consumo de cocaína no Brasil e 
à localização geográfica do país - vizinho dos maiores produtores de COC do mundo (Bolívia, Peru e Colômbia) - existem rotas importantes de abastecimento interno e aos mercados europeus e norte-americanos. Assim, a epidemiologia do esgoto poderia ser empregada na identificação de possíveis locais de refino e distribuição de COC no Brasil, uma vez que o aporte de COC diretamente na rede coletora de esgoto poderá alterar a razão entre concentrações de BE e COC comumente atribuída exclusivamente ao consumo. Outra perspectiva possível seria utilizar essa abordagem na proposição de um perfil de incidência de COC fumada, na forma de crack ou pasta base, por meio do monitoramento sistemático de AE e AEME, substâncias provenientes de processos térmicos de desidratação da cocaína.

\section{DETERMINAÇÃO DE DROGAS DE ABUSO E SEUS METABÓLITOS}

Por muito tempo, a determinação de drogas de abuso e de seus metabólitos esteve restrita a matrizes biológicas como sangue, urina, cabelo, entre outras. Apesar de apresentarem complexidade semelhante às amostras de interesse ambiental, em geral, tais matrizes apresentam concentrações mais elevadas das substâncias-alvo em comparação às amostras de águas superficiais e residuárias, por exemplo. Porém, com o desenvolvimento de técnicas analíticas capazes de detectar diversas espécies químicas sob níveis de concentração cada vez menores (ng $\mathrm{L}^{-1}$ a pg $\mathrm{L}^{-1}$ ), tornou-se possível a determinação de drogas de abuso e de outros contaminantes emergentes como fármacos, produtos de higiene pessoal e hormônios em matrizes ambientais. ${ }^{67}$

Contudo, devido à complexidade das matrizes investigadas e aos baixos níveis de concentração das substâncias de interesse, o desenvolvimento de métodos analíticos destinados à determinação não só de drogas de abuso, mas de diversas outras substâncias em matrizes ambientais é, atualmente, um dos mais importantes desafios da química analítica. A coeluição de interferentes durante a análise cromatográfica e a supressão do sinal analítico em métodos de ionização química são alguns dos inconvenientes em trabalhos desse tipo que utilizam, em sua vasta maioria, cromatógrafos acoplados a espectrômetros de massas. Logo, cada uma das etapas envolvidas na determinação dessas substâncias, desde a amostragem e preservação da amostra até a determinação dos analitos, precisa ser muito bem planejada e executada, de modo a levarem a informações fidedignas e representativas. Na Tabela 3 é apresentado um resumo das principais etapas envolvidas na determinação de drogas de abuso e de seus metabólitos em matrizes aquosas, assim como os procedimentos comumente adotados para amostragem, preservação e tratamento das amostras.

\section{Amostragem e preservação das amostras}

Na maior parte dos trabalhos envolvendo a determinação de drogas de abuso, a amostragem de águas superficiais, subterrâneas e para consumo humano é do tipo simples (instantânea), enquanto que, para amostras de esgoto bruto e tratado, se buscam obter amostras compostas ou acumuladas durante um período pré-estabelecido, geralmente, $24 \mathrm{~h}$ (Tabela 3). A utilização da amostragem acumulada, principalmente para as amostras de esgoto bruto, está relacionada às aplicações epidemiológicas já que, desta forma, a amostra obtida apresentará maior representatividade para a realização de estimativas de consumo.

Depois de coletadas, as amostras são comumente preservadas sob refrigeração, geralmente a $4{ }^{\circ} \mathrm{C}$, e em frascos de vidro âmbar até a extração ou análise direta. Contudo, essas condições não garantem, necessariamente, a estabilidade das substâncias-alvo nas amostras de esgoto bruto, tendo-se vista a intensa atividade biológica observada nestas matrizes. Nesse contexto, Castiglioni e colaboradores ${ }^{37}$ mostraram, com base em testes realizados em amostras de esgoto bruto enriquecidas com 16 resíduos de drogas de abuso, que todos os compostos sofreram variações de concentração após 3 dias de estocagem em frasco de vidro âmbar a $4{ }^{\circ} \mathrm{C}$. Em estudo mais recente, González-Mariño e colaboradores ${ }^{41}$ monitoraram a estabilidade de 7 drogas de abuso em esgoto bruto sob três condições diferentes durante 12 semanas. Na primeira condição, depois de filtradas e enriquecidas, as amostras foram estocadas em frascos de vidro âmbar a $4{ }^{\circ} \mathrm{C}$. Na segunda, foi adicionado $\mathrm{NaN}_{3}(0,2 \%)$, um biocida potente, às amostras e estas também foram estocadas em vidro âmbar a 4 ${ }^{\circ} \mathrm{C}$. Por fim, cartuchos de extração em fase sólida (SPE, solid phase extraction) foram utilizados para extração dos analitos em alíquotas de amostras de esgoto e, em seguida, estocados à $-20^{\circ} \mathrm{C}$ sem serem submetidos à etapa de eluição. Os resultados revelaram que, após 12 semanas, apenas os analitos preservados nos cartuchos de SPE não apresentaram degradação significativa.

Atualmente, grande parte dos trabalhos busca preservar amostras de esgoto por diminuição do $\mathrm{pH}$, filtração em membranas de diferentes porosidades e estocagem a $-20^{\circ} \mathrm{C}$ (Tabela 3). Entretanto, ainda não existe uma definição clara sobre qual ordem de execução destas etapas apresenta melhores resultados para a preservação dos analitos.

\section{Preparo de amostras}

O preparo de amostras é, sem dúvida, a etapa mais crítica de qualquer método analítico voltado à determinação de substâncias sob níveis de concentração traço em amostras ambientais. Devido às baixas concentrações das substâncias de interesse e, igualmente, à presença de interferentes na matriz, os métodos empregados envolvem, geralmente, uma etapa de pré-concentração e/ou clean up baseada em SPE (Tabela 3). Apesar de onerosa, a SPE é uma técnica de separação simples, de fácil automação e relativamente rápida quando comparada aos métodos clássicos de separação, tais como extração líquido-líquido, cromatografia líquida preparativa, entre outros. ${ }^{51,61,69}$ Os mecanismos de separação envolvidos nesta técnica podem ser baseados em processos físicos (exclusão por tamanho), químicos (adsorção, partição, troca iônica, ligação química etc.) ou ambos. A escolha de um ou mais desses mecanismos dependerá da natureza química das substâncias de interesse e da matriz analisada.

No caso da extração de drogas de abuso e de seus metabólitos, os adsorventes mais utilizados são aqueles que empregam copolímeros com propriedades hidrofílicas e lipofílicas como os cartuchos Oasis HLB $^{\circledR}$ (Waters) ou Strata-X ${ }^{\circledR}$ (Phenomex) ou adsorventes mistos baseados em fase reversa e troca cationica como a linha Oasis MCX $^{\circledR}$ (Waters) e Strata-XC ${ }^{\circledR}$ (Phenomenex). A influência de tipos de fases extratoras e parâmetros de extração tem sido bastante publicada. ${ }^{32,34,52,53,75,76}$ González-Mariño e colaboradores ${ }^{91}$ investigaram de forma pioneira o uso de polímero molecularmente impresso (MIP, molecularly imprinted polymer) para extração em fase sólida de AMP e obtiveram resultados satisfatórios.

A configuração on-line da SPE, apesar de pouco frequente, também tem sido aplicada para a determinação de drogas de abuso em matrizes aquáticas. Postigo e colaboradore ${ }^{17}$ descreveram o primeiro método baseado na extração SPE acoplada a um cromatógrafo líquido equipado com um espectrômetro de massas in tandem (LC-MS/ MS). Esse tipo de configuração apresenta algumas vantagens quando comparada à SPE off-line, tais como minimização de problemas relacionados à contaminação da amostra, menor exposição do analista a materiais perigosos (solventes orgânicos, por exemplo) e menor consumo de solventes e de amostra. ${ }^{8,17}$

Em detrimento à SPE, alguns poucos estudos propõem métodos 
Tabela 3. Métodos de amostragem, preservação, preparo das amostras e determinação analítica utilizados em estudos sobre drogas de abuso em águas naturais e residuárias urbanas

\begin{tabular}{|c|c|c|c|c|c|c|c|}
\hline Analito & Matriz & Amostragem & Preservação & $\begin{array}{l}\text { Quantidade de amostra } \\
\text { e fator de concentração } \\
\text { (FC) }\end{array}$ & Extração & $\begin{array}{l}\text { Determina- } \\
\text { ção }\end{array}$ & Ref. \\
\hline MAMP e MDMA & Efluente de ETE & $\begin{array}{l}\text { Passiva in situ } \\
\text { (POCIS) }\end{array}$ & Não informado & Não informado & $\begin{array}{l}\text { Polar Organic Chemical In- } \\
\text { tegrative Sampler (POCIS) }\end{array}$ & $\begin{array}{l}\text { HPLC- } \\
\text { ESI-MS } \\
\text { (IT) }\end{array}$ & 4 \\
\hline COC e BE & $\begin{array}{l}\text { Esgoto bruto e } \\
\text { água superficial }\end{array}$ & Acumulada (24h) & $\begin{array}{l}\text { Refrigeração à } 4 \\
{ }^{\circ} \mathrm{C} \text { e extração em } \\
3 \text { dias }\end{array}$ & $\begin{array}{l}500 \mathrm{~mL} \text { de amostra filtra- } \\
\mathrm{da}(\mathrm{FC}=5000)\end{array}$ & $\begin{array}{l}\text { SPE com Oasis MCX (Wa- } \\
\text { ters) }\end{array}$ & $\begin{array}{l}\text { HPLC- } \\
\text { ESI-MS/ } \\
\text { MS (QqQ) }\end{array}$ & 5 \\
\hline AMP & Lodo de ETE & Instantânea & Não informado & $\begin{array}{l}500 \mathrm{~mL} \text { de suspensão } 50 \\
\mathrm{~g} \mathrm{~L}^{-1}(\mathrm{FC}=500)\end{array}$ & $\begin{array}{l}\text { SPE com Oasis HLB (Wa- } \\
\text { ters) }\end{array}$ & $\begin{array}{l}\text { HPLC- } \\
\text { API-MS } \\
\text { (IT) }\end{array}$ & 58 \\
\hline $\begin{array}{l}\text { BE, MOR, COD, MTD e } \\
\text { outros }\end{array}$ & $\begin{array}{l}\text { Esgoto bruto, } \\
\text { efluente de ETE, } \\
\text { água superficial, } \\
\text { água subterrânea } \\
\text { e água para con- } \\
\text { sumo }\end{array}$ & Instantânea & $\begin{array}{l}\text { Refrigeração à } 4 \\
{ }^{\circ} \mathrm{C} \text { e extração em } \\
1 \text { dia. }\end{array}$ & $\begin{array}{l}100 \mathrm{~mL} \text { de esgoto e } \\
\text { efluente }(\mathrm{FC}=200), 200 \\
\mathrm{~mL} \text { de efluente de ETE } \\
(\mathrm{FC}=400) \text { e } 1000 \mathrm{~mL} \text { de } \\
\text { água superficial, subterrâ- } \\
\text { nea e para consumo }(\mathrm{FC}= \\
\text { 2000). Amostras filtradas }\end{array}$ & $\begin{array}{l}\text { SPE com Oasis HLB (Wa- } \\
\text { ters) }\end{array}$ & $\begin{array}{l}\text { HPLC- } \\
\text { ESI-MS/ } \\
\text { MS (QqQ) }\end{array}$ & 49 \\
\hline $\begin{array}{l}\text { THC, THC-COOH, COC, } \\
\text { BE, CE, Nor-COC, Nor- } \\
\text { BE, MOR, 6AM; MTD, } \\
\text { EDDP AMP, MAMP, MDA, } \\
\text { MDMA e MDEA }\end{array}$ & $\begin{array}{l}\text { Esgoto bruto e } \\
\text { efluente de ETE }\end{array}$ & Acumulada (24h) & $\begin{array}{l}\text { Refrigeração no } \\
\text { escuro em fras- } \\
\text { co de vidro à } 4 \\
{ }^{\circ} \mathrm{C} \text { e extração em } \\
3 \text { dias } \\
\end{array}$ & $\begin{array}{l}50 \mathrm{~mL} \text { de amostra filtrada } \\
(\mathrm{FC}=250)\end{array}$ & $\begin{array}{l}\text { SPE com Oasis MCX (Wa- } \\
\text { ters) }\end{array}$ & $\begin{array}{l}\text { HPLC-MS/ } \\
\text { MS (QqQ) }\end{array}$ & 37 \\
\hline $\begin{array}{l}\text { COC, BE, AMP, MAMP, } \\
\text { MDA, MDMA, MDEA e } \\
\text { LSD }\end{array}$ & $\begin{array}{l}\text { Esgoto bruto, } \\
\text { efluente de ETE } \\
\text { e água superficial }\end{array}$ & $\begin{array}{l}\text { Esgoto e efluente: } \\
\text { acumulada ( } 24 \mathrm{~h}) \\
\text { Água superficial: } \\
\text { Instantânea }\end{array}$ & $\begin{array}{l}\text { Refrigeração no } \\
\text { escuro em fras- } \\
\text { co de vidro à } 4 \\
{ }^{\circ} \mathrm{C} \text { e extração em } \\
1 \text { dia } \\
\end{array}$ & $\begin{array}{l}100 \mathrm{~mL} \text { de amostra filtra- } \\
\text { da }(\mathrm{FC}=200)\end{array}$ & $\begin{array}{l}\text { SPE com Oasis HLB (Wa- } \\
\text { ters) }\end{array}$ & $\begin{array}{l}\text { UPLC- } \\
\text { ESI-MS/ } \\
\text { MS (QqQ) }\end{array}$ & 39 \\
\hline $\begin{array}{l}\text { COC, BE, CE, MOR, MTD, } \\
\text { EDDP MDMA e LSD }\end{array}$ & $\begin{array}{l}\text { Esgoto bruto, } \\
\text { efluente de ETE } \\
\text { e água superficial }\end{array}$ & $\begin{array}{l}\text { Esgoto e efluente: } \\
\text { acumulada }(24 \mathrm{~h}) \mathrm{e} \\
\text { instantânea. } \\
\text { Água superficial: } \\
\text { Instantânea } \\
\end{array}$ & $\begin{array}{l}\text { Extração em } 1 \\
\text { dia }\end{array}$ & $\begin{array}{l}500 \mathrm{~mL} \text { de amostra filtra- } \\
\text { da }(\mathrm{FC}=2500)\end{array}$ & $\begin{array}{l}\text { SPE com Strata-X, Strata-XC } \\
\text { e Strata-XCW (Phenomenex) }\end{array}$ & $\begin{array}{l}\text { HPLC-MS/ } \\
\text { MS }\end{array}$ & 35 \\
\hline $\mathrm{COC}, \mathrm{BE}, \mathrm{e} \mathrm{AMP}$ & Água superficial & Instantânea & $\begin{array}{l}\text { Acidificação a } \\
\text { pH } 2,5 \text {, filtração, } \\
\text { refrigeração a } 4 \\
\text { oC e extração } \\
\text { em } 1 \text { semana }\end{array}$ & $\begin{array}{l}1000 \mathrm{~mL} \text { de amostra fil- } \\
\text { trada }(\mathrm{FC}=2000)\end{array}$ & $\begin{array}{l}\text { SPE com Oasis HLB, Oasis } \\
\text { MCX, Oasis MAX, Oasis } \\
\text { WCX, Oasis WAX (Wa- } \\
\text { ters), Chromabond C18ec } \\
\text { (Anachem), Isolute ENV+, } \\
\text { Isolute HCX (Biotage), }\end{array}$ & $\begin{array}{l}\text { UPLC- } \\
\text { ESI-MS/ } \\
\text { MS (QqQ) }\end{array}$ & 75 \\
\hline $\begin{array}{l}\text { THC-COOH, COC, BE, CE, } \\
\text { Nor-COC, Nor-BE, MOR, } \\
\text { 6AM, COD, 6AC, MTD, } \\
\text { EDDP, AMP, MAMP, MDA } \\
\text { e MDMA }\end{array}$ & Água superficial & Acumulada (2h) & Não informado & $\begin{array}{l}250 \text { a } 1000 \mathrm{~mL} \text { de amos- } \\
\text { tra filtrada (FC entre } 1250 \\
\text { e 5000) }\end{array}$ & $\begin{array}{l}\text { SPE com Oasis MCX (Wa- } \\
\text { ters) }\end{array}$ & $\begin{array}{l}\text { HPLC- } \\
\text { ESI-MS/ } \\
\text { MS (QqQ) }\end{array}$ & 15 \\
\hline $\begin{array}{l}\text { THC, THC-COOH, OH- } \\
\text { THC, COC, BE, CE, HER, } \\
\text { MOR, 6AM, AMP, MAMP, } \\
\text { MDMA, LSD, nor-LSD, } \\
\text { O-H-LSD e outros }\end{array}$ & $\begin{array}{l}\text { Esgoto bruto e } \\
\text { efluente de ETE }\end{array}$ & Acumulada (24h) & $\begin{array}{l}\text { Armazenamento } \\
\text { à }-20^{\circ} \mathrm{C}\end{array}$ & $\begin{array}{l}5 \text { mL de amostra filtrada } \\
\text { em sistema de extração } \\
\text { on-line (FC não infor- } \\
\text { mado) }\end{array}$ & $\begin{array}{l}\text { SPE com Oasis HLB (Wa- } \\
\text { ters), fase polimérica PLRP } \\
\text { (Spark Holland) e Isolute C18 } \\
\text { EC (Biotage) }\end{array}$ & $\begin{array}{l}\text { HPLC- } \\
\text {-ESI-MS/ } \\
\text { MS híbrido } \\
\text { (QqQ e IT) }\end{array}$ & 17 \\
\hline COC, BE e AMP & $\begin{array}{l}\text { Esgoto Bruto e } \\
\text { Água superficial }\end{array}$ & Instantânea & $\begin{array}{l}\text { Acidificação a } \\
\text { pH } 2 \text { e refrige- } \\
\text { ração à } 4^{\circ} \mathrm{C}\end{array}$ & $\begin{array}{l}250 \mathrm{~mL} \text { para esgoto }(\mathrm{FC}= \\
500) \text { e } 1000 \mathrm{~mL} \text { para água } \\
\text { superficial }(\mathrm{FC}=2000) . \\
\text { Amostras filtradas }\end{array}$ & $\begin{array}{l}\text { SPE com Oasis HLB, Oasis } \\
\text { MCX, Oasis MAX, Oasis } \\
\text { WCX, Oasis WAX (Wa- } \\
\text { ters), Chromabond C18ec } \\
\text { (Anachem), Isolute ENV+, } \\
\text { Isolute HCX (Biotage), }\end{array}$ & $\begin{array}{c}\text { UPLC- } \\
\text { ESI-MS/ } \\
\text { MS (QqQ) }\end{array}$ & 76 \\
\hline $\mathrm{COC}, \mathrm{BE}$ e AMP & Água superficial & Instantânea & Não informado & $\begin{array}{l}1000 \mathrm{~mL} \text { de amostra fil- } \\
\text { trada }(\mathrm{FC}=2000)\end{array}$ & $\begin{array}{l}\text { SPE com Oasis MCX (Wa- } \\
\text { ters) }\end{array}$ & $\begin{array}{c}\text { UPLC- } \\
\text { ESI-MS/ } \\
\text { MS (QqQ) }\end{array}$ & 47 \\
\hline $\begin{array}{l}\text { COC e BE, AMP, MAMP, } \\
\text { MDA, MDMA, MDEA, } \\
\text { PCP e LSD }\end{array}$ & $\begin{array}{l}\text { Esgoto bruto e } \\
\text { efluente de ETE }\end{array}$ & $\begin{array}{l}\text { Instantânea e acu- } \\
\text { mulada (24h). }\end{array}$ & $\begin{array}{l}\text { Refrigeração no } \\
\text { escuro à } 4{ }^{\circ} \mathrm{C} \text { e } \\
\text { extração em } 1 \\
\text { dia }\end{array}$ & $\begin{array}{l}100 \mathrm{~mL} \text { de amostra filtra- } \\
\text { da }(\mathrm{FC}=200)\end{array}$ & $\begin{array}{l}\text { SPE com Oasis HLB (Wa- } \\
\text { ters) }\end{array}$ & $\begin{array}{l}\text { UPLC- } \\
\text { ESI-MS/ } \\
\text { MS (QqQ) }\end{array}$ & 6 \\
\hline $\begin{array}{l}\text { COC, BE, AMP, MAMP, } \\
\text { MDA MDMA }\end{array}$ & $\begin{array}{l}\text { Água superficial } \\
\text { e água para } \\
\text { consumo }\end{array}$ & $\begin{array}{l}\text { Acumulada em } \\
\text { função da vazão }\end{array}$ & $\begin{array}{l}\text { Refrigeração no } \\
\text { escuro à } 4{ }^{\circ} \mathrm{C} \text { e } \\
\text { adição de áci- } \\
\text { do ascórbico na } \\
\text { água para con- } \\
\text { sumo }\end{array}$ & $\begin{array}{l}100 \mathrm{~mL} \text { de amostra filtra- } \\
\text { da }(\mathrm{FC}=200)\end{array}$ & $\begin{array}{l}\text { SPE com Oasis HLB (Wa- } \\
\text { ters) }\end{array}$ & $\begin{array}{l}\text { UPLC- } \\
\text { ESI-MS/ } \\
\text { MS (QqQ) }\end{array}$ & 28 \\
\hline
\end{tabular}


Tabela 3. continuação,

\begin{tabular}{|c|c|c|c|c|c|c|c|}
\hline Analito & Matriz & Amostragem & Preservação & $\begin{array}{l}\text { Quantidade de amostra } \\
\text { e fator de concentração } \\
\text { (FC) }\end{array}$ & Extração & $\begin{array}{l}\text { Determina- } \\
\text { ção }\end{array}$ & Ref. \\
\hline $\begin{array}{l}\text { THC-COOH, COC, BE, } \\
\text { MOR, 6AM AMP, MAMP } \\
\text { e MDMA }\end{array}$ & Esgoto bruto & $\begin{array}{l}\text { Acumulada em } \\
\text { função da vazão } \\
(24 \mathrm{~h})\end{array}$ & Não informado & Não informado & $\begin{array}{l}\text { SPE com Oasis MCX (Wa- } \\
\text { ters) }\end{array}$ & $\begin{array}{l}\text { HPLC-MS/ } \\
\text { MS (QqQ) }\end{array}$ & 77 \\
\hline $\mathrm{BE}$ & $\begin{array}{l}\text { Esgoto bruto e } \\
\text { água superficial }\end{array}$ & Não informado & Não informado & Não informado & Não informado & $\begin{array}{l}\text { UPLC-MS/ } \\
\text { MS (QqQ) }\end{array}$ & 78 \\
\hline COC, BE e EME & $\begin{array}{l}\text { Esgoto bruto e } \\
\text { água superficial }\end{array}$ & $\begin{array}{l}\text { Esgoto: acumula- } \\
\text { da (24h) } \\
\text { Água superficial: } \\
\text { Instantânea. }\end{array}$ & $\begin{array}{l}\text { Acidificação a } \\
\text { pH } 2 \text { e armaze- } \\
\text { namento à }-20 \\
{ }^{\circ} \mathrm{C}\end{array}$ & $\begin{array}{l}100 \mathrm{~mL} \text { para esgoto e } 500 \\
\mathrm{~mL} \text { para água superficial } \\
\text { (FC não informado) }\end{array}$ & $\begin{array}{l}\text { SPE com Oasis HLB e Oa- } \\
\text { sis MCX (Waters), Isolute } \\
\text { ENV+, Isolute C18 EC, Iso- } \\
\text { lute PH (Biotage), Bond Elut } \\
\text { Certify (Agilent) e Chr-- } \\
\text { mabond Easy (Macherey- } \\
\text { Nagel); }\end{array}$ & $\begin{array}{c}\text { HPLC- } \\
\text { ESI-MS/ } \\
\text { MS (QqQ) }\end{array}$ & 34 \\
\hline $\begin{array}{l}\text { COC, BE, nor-COC, nor- } \\
\text { BE, AMP, MAMP, MDA, } \\
\text { MDMA, MDEA, MBDB, } \\
\text { PCP, LSD e O-H-LSD }\end{array}$ & Esgoto bruto & $\begin{array}{l}\text { Acumulada em } \\
\text { função da vazão } \\
(6 \mathrm{~h})\end{array}$ & $\begin{array}{l}\text { Armazenamen- } \\
\text { to à }-20{ }^{\circ} \mathrm{C} \text { e } \\
\text { extração em } 3 \\
\text { semanas }\end{array}$ & Injeção direta $(1800 \mu \mathrm{L})$ & Não houve extração & $\begin{array}{c}\text { HPLC- } \\
\text {-ESI-MS/ } \\
\text { MS (QqQ) }\end{array}$ & 18 \\
\hline COC, BE e EME & $\begin{array}{l}\text { Esgoto bruto e } \\
\text { água superficial }\end{array}$ & $\begin{array}{l}\text { Esgoto: Acumu- } \\
\text { lada em função da } \\
\text { vazão (24h) } \\
\text { Água superficial: } \\
\text { Instantânea } \\
\end{array}$ & $\begin{array}{l}\text { Acidificação a } \\
\text { pH } 2 \text { e armaze- } \\
\text { namento à }-20 \\
{ }^{\circ} \mathrm{C}\end{array}$ & $\begin{array}{l}100 \mathrm{~mL} \text { de amostra filtra- } \\
\text { da }(\mathrm{FC}=1000)\end{array}$ & $\begin{array}{l}\text { SPE com Oasis HLB (Wa- } \\
\text { ters) }\end{array}$ & $\begin{array}{l}\text { HPLC- } \\
\text { ESI-MS } \\
\text { (IT) }\end{array}$ & 46 \\
\hline $\mathrm{COC}, \mathrm{BE}, \mathrm{COD}$ e AMP & $\begin{array}{l}\text { Esgoto bruto e } \\
\text { água superficial }\end{array}$ & $\begin{array}{l}\text { Acumulada (24 h) } \\
\text { e Instantânea }\end{array}$ & $\begin{array}{l}\text { Acidificação a } \\
\text { pH } 2 \text { e filtração }\end{array}$ & $\begin{array}{l}250 \mathrm{~mL} \text { para esgoto }(\mathrm{FC}= \\
500) \text { e } 1000 \mathrm{~mL} \text { para água } \\
\text { superficial }(\mathrm{FC}=2000) . \\
\text { Amostras filtradas }\end{array}$ & $\begin{array}{l}\text { SPE com Oasis MCX (Wa- } \\
\text { ters) }\end{array}$ & $\begin{array}{c}\text { UPLC- } \\
\text { ESI-MS/ } \\
\text { MS (QqQ) }\end{array}$ & 79 \\
\hline MAMP e MDMA & $\begin{array}{l}\text { Esgoto bruto, } \\
\text { efluente de ETE, } \\
\text { etapas de trata- } \\
\text { mento em ETE e } \\
\text { água superficial } \\
\end{array}$ & Instantânea & $\begin{array}{l}\text { Armazenamento } \\
\text { à }-20^{\circ} \mathrm{C}\end{array}$ & $\begin{array}{l}\text { Até } 250 \mathrm{~mL} \text { de amostra } \\
\text { filtrada (FC variável) }\end{array}$ & $\begin{array}{l}\text { SPE com Oasis HLB (Wa- } \\
\text { ters) }\end{array}$ & $\begin{array}{l}\text { UPLC- } \\
\text { ESI-MS } \\
\text { (IT) }\end{array}$ & 80 \\
\hline $\mathrm{COC}$ e $\mathrm{BE}$ & $\begin{array}{l}\text { Esgoto bruto, } \\
\text { efluente de ETE } \\
\text { e água superficial }\end{array}$ & $\begin{array}{l}\text { Esgoto: Acumu- } \\
\text { lada em função da } \\
\text { vazão (24h) } \\
\text { Água superficial: } \\
\text { Instantânea } \\
\end{array}$ & $\begin{array}{l}\text { Acidificação a } \\
\text { pH } 2 \text { e armaze- } \\
\text { namento à }-20 \\
{ }^{\circ} \mathrm{C}\end{array}$ & Não informado & $\begin{array}{l}\text { SPE com Oasis HLB (Wa- } \\
\text { ters) }\end{array}$ & $\begin{array}{c}\text { HPLC- } \\
\text { ESI-MS/ } \\
\text { MS (QqQ) }\end{array}$ & 81 \\
\hline AMP e MAMP & $\begin{array}{l}\text { Efluente de ETE } \\
\text { e água superficial }\end{array}$ & $\begin{array}{l}\text { Passiva in situ } \\
\text { (POCIS) }\end{array}$ & Não informado & Não informado & $\begin{array}{l}\text { Polar Organic Chemical In- } \\
\text { tegrative Sampler (POCIS) }\end{array}$ & $\begin{array}{l}\text { HPLC- } \\
\text {-ESI-MS/ } \\
\text { MS (QqQ) }\end{array}$ & 82 \\
\hline COC, BE e EME & Esgoto bruto & $\begin{array}{l}\text { Acumulada em } \\
\text { função da vazão } \\
\text { (24h) }\end{array}$ & Não informado & $\begin{array}{l}100 \mathrm{~mL} \text { de amostra filtra- } \\
\text { da }(\mathrm{FC}=1000)\end{array}$ & $\begin{array}{l}\text { SPE com Oasis HLB (Wa- } \\
\text { ters) }\end{array}$ & $\begin{array}{l}\text { HPLC- } \\
\text { ESI-MS } \\
\text { (IT) }\end{array}$ & 83 \\
\hline COC, BE, COD e AMP & Esgoto bruto & $\begin{array}{l}\text { Acumulada (24 h) } \\
\text { e Instantânea }\end{array}$ & $\begin{array}{l}\text { Acidificação a } \\
\text { pH } 2\end{array}$ & $\begin{array}{l}1000 \mathrm{~mL} \text { de amostra fil- } \\
\text { trada }(\mathrm{FC}=2000)\end{array}$ & $\begin{array}{l}\text { SPE com Oasis MCX (Wa- } \\
\text { ters) }\end{array}$ & $\begin{array}{l}\text { UPLC- } \\
\text { ESI-MS/ } \\
\text { MS (QqQ) }\end{array}$ & 84 \\
\hline $\mathrm{COC}, \mathrm{BE}$ e $\mathrm{MOR}$ & Esgoto bruto & Instantânea & $\begin{array}{l}\text { Refrigeração à } 4 \\
{ }^{\circ} \mathrm{C} \text { e extração em } \\
3 \text { dias }\end{array}$ & Não informado & $\begin{array}{l}\text { SPE com Bond Elut Certify } \\
\text { LRC (Agilent) }\end{array}$ & $\begin{array}{l}\text { GC-MS } \\
\text { com deri- } \\
\text { vatização }\end{array}$ & 42 \\
\hline $\begin{array}{l}\text { COC, BE, EME, 6AM, } \\
\text { MTD, EDDP, AMP, MAMP } \\
\text { e MDMA }\end{array}$ & Esgoto bruto & $\begin{array}{l}\text { Acumulada em } \\
\text { função da vazão } \\
\text { (24h) }\end{array}$ & $\begin{array}{l}\text { Acidificação a } \\
\text { pH } 2 \text { e armaze- } \\
\text { namento à }-20 \\
{ }^{\circ} \mathrm{C}\end{array}$ & $\begin{array}{l}50 \mathrm{~mL} \text { de amostra filtrada } \\
(\mathrm{FC}=250)\end{array}$ & $\begin{array}{l}\text { SPE com Oasis HLB e Oasis } \\
\text { MCX (Waters) }\end{array}$ & $\begin{array}{l}\text { HPLC- } \\
\text { ESI-MS/ } \\
\text { MS (QqQ) }\end{array}$ & 38 \\
\hline $\begin{array}{l}\text { THC, THC-COOH, HER, } \\
\text { MOR, 6AM, Nor-MOR, } \\
\text { COD, MTD, EDDP e outros }\end{array}$ & $\begin{array}{l}\text { Esgoto bruto, } \\
\text { efluente de ETE, } \\
\text { água superficial } \\
\text { e água para con- } \\
\text { sumo }\end{array}$ & $\begin{array}{l}\text { Esgoto: acumula- } \\
\text { da (24h) } \\
\text { Água superficial } \\
\text { e para consumo: } \\
\text { Instantânea }\end{array}$ & $\begin{array}{l}\text { Refrigeradas no } \\
\text { escuro a } 4^{\circ} \mathrm{C} \text {. } \\
\text { Adição de Na- } \\
{ }_{2} \mathrm{~S}_{2} \mathrm{O}_{3} \text { na água } \\
\text { para consumo. } \\
\text { Extração em } 3 \\
\text { dias }\end{array}$ & $\begin{array}{l}200 \mathrm{~mL} \text { de amostra filtra- } \\
\text { da }(\mathrm{FC}=400)\end{array}$ & $\begin{array}{l}\text { SPE com Oasis HLB (Wa- } \\
\text { ters) }\end{array}$ & $\begin{array}{l}\text { UPLC- } \\
\text { ESI-MS/ } \\
\text { MS (QqQ) }\end{array}$ & 54 \\
\hline $\begin{array}{l}\text { THC-COOH, COC, BE, CE, } \\
\text { Nor-COC, Nor-BE, AMP, } \\
\text { MAMP, MDA, MDMA e } \\
\text { MDEA }\end{array}$ & $\begin{array}{l}\text { Esgoto bruto, } \\
\text { efluente de ETE } \\
\text { e água superficial }\end{array}$ & $\begin{array}{l}\text { Esgoto e efluente: } \\
\text { acumulada (24h) } \\
\text { Água superficial: } \\
\text { Instantânea }\end{array}$ & $\begin{array}{l}\text { Armazenamento } \\
\text { à }-20^{\circ} \mathrm{C}\end{array}$ & $\begin{array}{l}50 \mathrm{~mL} \text { de de água superfi- } \\
\text { cial e efluente de ETE (FC } \\
=50 \text { ). } 50 \mathrm{~mL} \text { de de esgoto } \\
\text { diluído } 5 \text { vezes }(\mathrm{FC}=10 \text { ). } \\
\text { Amostras filtradas }\end{array}$ & $\begin{array}{l}\text { SPE com Oasis MCX (Wa- } \\
\text { ters) }\end{array}$ & $\begin{array}{l}\text { UPLC- } \\
\text { ESI-MS/ } \\
\text { MS (QqQ) }\end{array}$ & 85 \\
\hline $\begin{array}{l}\text { THC, THC-COOH, OH- } \\
\text { THC, COC, BE, CE, HER, } \\
\text { MOR, 6AM, AMP, MAMP, } \\
\text { MDMA, LSD, nor-LSD, } \\
\text { O-H-LSD e outros }\end{array}$ & $\begin{array}{l}\text { Esgoto bruto, } \\
\text { efluente de ETE } \\
\text { e água superficial }\end{array}$ & $\begin{array}{l}\text { Esgoto e efluente: } \\
\text { acumulada (24h) } \\
\text { Água superficial: } \\
\text { Instantânea }\end{array}$ & $\begin{array}{l}\text { Filtração }(0,45 \\
\mu \mathrm{m}) \text { e armazena- } \\
\text { mento à }-20^{\circ} \mathrm{C}\end{array}$ & $\begin{array}{l}5 \mathrm{~mL} \text { de amostra filtrada } \\
\text { em sistema de extração } \\
\text { on-line (FC não infor- } \\
\text { mado) }\end{array}$ & $\begin{array}{l}\text { SPE com Oasis HLB (Wa- } \\
\text { ters) e fase polimérica PLRP } \\
\text { (Spark Holland) }\end{array}$ & $\begin{array}{c}\text { HPLC- } \\
\text {-ESI-MS/ } \\
\text { MS híbrido } \\
\text { (QqQ e IT) }\end{array}$ & 8 \\
\hline
\end{tabular}


Tabela 3. continuação,

\begin{tabular}{|c|c|c|c|c|c|c|c|}
\hline Analito & Matriz & Amostragem & Preservação & $\begin{array}{l}\text { Quantidade de amostra } \\
\text { e fator de concentração } \\
\text { (FC) }\end{array}$ & Extração & $\begin{array}{l}\text { Determina- } \\
\text { ção }\end{array}$ & Ref. \\
\hline $\begin{array}{l}\text { THC-COOH, COC, BE, } \\
\text { CE, HER, MOR, COD, } \\
\text { MTD, AMP, MAMP, MDA, } \\
\text { MDMA e MDEA }\end{array}$ & $\begin{array}{l}\text { Esgoto bruto, } \\
\text { efluente de ETE } \\
\text { e água superficial }\end{array}$ & Não informado & $\begin{array}{l}\text { Extração em } 1 \\
\text { dia } \\
\text { Testes com adi- } \\
\text { ção de azida de } \\
\text { sódio. }\end{array}$ & $\begin{array}{l}100 \mathrm{~mL} \text { de esgoto, } 200 \\
\mathrm{~mL} \text { de efluente de ETE e } \\
500 \mathrm{~mL} \text { de água superfi- } \\
\text { cial. (FC não informado). } \\
\text { Amostras filtradas }\end{array}$ & $\begin{array}{l}\text { SPE com Oasis HLB (Wa- } \\
\text { ters) }\end{array}$ & $\begin{array}{l}\text { GC-MS/ } \\
\text { MS com } \\
\text { derivatiza- } \\
\text { ção }\end{array}$ & 41 \\
\hline $\begin{array}{l}\text { COC, BE, AMP, MDMA } \\
\text { e outros }\end{array}$ & $\begin{array}{l}\text { Esgoto bruto e } \\
\text { efluente de ETE }\end{array}$ & $\begin{array}{l}\text { Acumulada em } \\
\text { função da vazão } \\
(24 h)\end{array}$ & $\begin{array}{l}\text { Refrigeração à } \\
4^{\circ} \mathrm{C} \text { e extração } \\
\text { em } 24 \text { h }\end{array}$ & $\begin{array}{l}250 \mathrm{~mL} \text { de esgoto }(\mathrm{FC}= \\
500) \text { e } 500 \mathrm{~mL} \mathrm{de} \text { efluen- } \\
\text { te de ETE }(\mathrm{FC}=100) \text {. } \\
\text { Amostras filtradas }\end{array}$ & $\begin{array}{l}\text { SPE com Oasis HLB (Wa- } \\
\text { ters) }\end{array}$ & $\begin{array}{l}\text { HPLC- } \\
\text { ESI-MS/ } \\
\text { MS (QqQ) }\end{array}$ & 43 \\
\hline $\begin{array}{l}\text { COC, BE, MOR, 6AM, } \\
\text { COD, 6AC - MAMP }\end{array}$ & $\begin{array}{l}\text { Esgoto Bruto, } \\
\text { efluente de ETE } \\
\text { e água superficial }\end{array}$ & $\begin{array}{l}\text { Esgoto e efluen- } \\
\text { te: acumulada em } \\
\text { função da vazão } \\
\text { (10-12 h) } \\
\text { Água superficial: } \\
\text { Instantânea } \\
\end{array}$ & $\begin{array}{l}\text { Fltração, acidi- } \\
\text { ficação a pH } 2 \\
\text { e refrigeração } \\
\text { a } 4{ }^{\circ} \mathrm{C}\end{array}$ & $\begin{array}{l}200 \mathrm{~mL} \text { de amostra filtra- } \\
\text { da }(\mathrm{FC}=500)\end{array}$ & $\begin{array}{l}\text { SPE com Oasis MCX (Wa- } \\
\text { ters) }\end{array}$ & $\begin{array}{l}\text { HPLC- } \\
\text { ESI-MS/ } \\
\text { MS (QqQ) }\end{array}$ & 86 \\
\hline $\begin{array}{l}\text { THC-COOH, COC, BE, } \\
\text { MOR, 6AM, COD, 6AC, } \\
\text { EDDP, AMP e MAMP }\end{array}$ & $\begin{array}{l}\text { Esgoto bruto, } \\
\text { efluente de ETE } \\
\text { e água superficial }\end{array}$ & $\begin{array}{l}\text { Esgoto e efluen- } \\
\text { te: acumulada em } \\
\text { função da vazão } \\
\text { (24 h) } \\
\text { Água superficial: } \\
\text { Instantânea } \\
\end{array}$ & $\begin{array}{l}\text { Acidificação a } \\
\text { pH 2, filtração, } \\
\text { refrigeração no } \\
\text { escuro a } 4{ }^{\circ} \mathrm{C} \\
\text { e extração em } \\
48 \mathrm{~h}\end{array}$ & Injeção direta $(100 \mu \mathrm{L})$ & Não houve extração & $\begin{array}{l}\text { HPLC- } \\
\text {-ESI-MS/ } \\
\text { MS (QqQ) }\end{array}$ & 50 \\
\hline $\begin{array}{l}\text { COC, ECG, BE, EME, CE, } \\
\text { AE, AEME, Nor-COC, Nor- } \\
\text { BE, MOR, 6AM, AMP, } \\
\text { MAMP, MDMA, MDEA, } \\
\text { MBDB e outros } \\
\end{array}$ & Esgoto bruto & $\begin{array}{l}\text { Acumulada em } \\
\text { função da vazão } \\
(24 \text { h) }\end{array}$ & Não informado & $\begin{array}{l}200 \mathrm{~mL} \text { de amostra filtra- } \\
\text { da }(\mathrm{FC}=400)\end{array}$ & $\begin{array}{l}\text { SPE com Oasis HLB e Oasis } \\
\text { MCX (Waters), Strata-X e } \\
\text { Strata-XC (Phenomenex) } \\
\text { Bond Elut Certify (Agilent) } \\
\text { e Clean Screen (UCT) }\end{array}$ & $\begin{array}{l}\text { HPLC- } \\
\text { ESI-MS/ } \\
\text { MS (QqQ) }\end{array}$ & 53 \\
\hline $\begin{array}{l}\text { COC, BE, AMP, MAMP, } \\
\text { MDA MDMA }\end{array}$ & $\begin{array}{l}\text { Esgoto bruto, } \\
\text { efluente de ETE } \\
\text { e material parti- } \\
\text { culado }\end{array}$ & $\begin{array}{l}\text { Acumulada (24h) } \\
\text { e instantânea }\end{array}$ & $\begin{array}{l}\text { Refrigeração à } \\
4{ }^{\circ} \mathrm{C} \text { e extração } \\
\text { em } 48 \mathrm{~h}\end{array}$ & $\begin{array}{l}100 \mathrm{~mL} \text { de esgoto }(\mathrm{FC}= \\
250) \text { e } 200 \mathrm{~mL} \text { de efluen- } \\
\text { te de ETE }(\mathrm{FC}=500) \text {. } \\
\text { Amostras filtradas }\end{array}$ & $\begin{array}{l}\text { SPE com Oasis MCX (Wa- } \\
\text { ters) } \\
\text { Para material suspenso, soni- } \\
\text { cação de filtros em metanol }\end{array}$ & $\begin{array}{l}\text { HPLC- } \\
\text {-ESI-MS/ } \\
\text { MS híbrido } \\
\text { (QqQ e IT) }\end{array}$ & 33 \\
\hline $\begin{array}{l}\text { THC-COOH, COC, BE, } \\
\text { MOR, 6AM, COD, MTD, } \\
\text { EDDP, AMP e MDMA }\end{array}$ & $\begin{array}{l}\text { Esgoto bruto e } \\
\text { efluente de ETE }\end{array}$ & $\begin{array}{l}\text { Acumulada em } \\
\text { função da vazão } \\
(24 \mathrm{~h})\end{array}$ & Extração em $3 \mathrm{~h}$ & $\begin{array}{l}200 \mathrm{~mL} \text { de esgoto }(\mathrm{FC}= \\
200) \text { e } 500 \mathrm{~mL} \mathrm{de} \text { efluen- } \\
\text { te de ETE }(\mathrm{FC}=500) \text {. } \\
\text { Amostras filtradas }\end{array}$ & $\begin{array}{l}\boldsymbol{S P E} \text { com Oasis HLB (Wa- } \\
\text { ters) }\end{array}$ & $\begin{array}{c}\text { HPLC- } \\
\text { ESI-MS/ } \\
\text { MS (QqQ) }\end{array}$ & 40 \\
\hline $\begin{array}{l}\text { THC, THC-COOH, COC, } \\
\text { BE, EME, HER, MOR, } \\
\text { 6AM, COD, MTD, AMP, } \\
\text { MAMP, MDA MDMA }\end{array}$ & Água superficial & Instantânea & $\begin{array}{l}\text { Armazenamen- } \\
\text { to à }-20{ }^{\circ} \mathrm{C} \text { e } \\
\text { extração em } 1 \\
\text { semana }\end{array}$ & $\begin{array}{l}50,250 \text { e } 500 \mathrm{~mL} \text { de } \\
\text { amostra filtrada }(50 x, \\
250 x \text { e } 500 x \text {, respectiva- } \\
\text { mente) }\end{array}$ & $\begin{array}{l}\text { SPE com Oasis HLB, Oasis } \\
\text { MCX e Oasis WAX, Su- } \\
\text { pel-Select HLB (Supelco), } \\
\text { Strata-X, Strata-XC e Strata- } \\
\text {-XCW (Phenomenex) }\end{array}$ & $\begin{array}{l}\text { HPLC- } \\
\text {-ESI-MS/ } \\
\text { MS (QqQ) }\end{array}$ & 52 \\
\hline $\begin{array}{l}\text { THC, THC-COOH, OH- } \\
\text { THC, COC, BE, CE, HER, } \\
\text { MOR, 6AM, MTD, EDDP, } \\
\text { AMP, MAMP, MDMA, } \\
\text { LSD, Nor-LSD, O-H-LSD } \\
\text { e outros }\end{array}$ & Esgoto bruto & $\begin{array}{l}\text { Acumulada em } \\
24 \mathrm{~h}\end{array}$ & $\begin{array}{l}\text { Armazenamen- } \\
\text { to no escuro em } \\
\text { frasco PET à } \\
-20^{\circ} \mathrm{C}\end{array}$ & $\begin{array}{l}5 \mathrm{~mL} \text { de amostra filtrada } \\
\text { em sistema de extração } \\
\text { on-line (FC não infor- } \\
\text { mado) }\end{array}$ & $\begin{array}{l}\text { SPE com fase polimérica } \\
\text { PLRP (Spark Holland) }\end{array}$ & $\begin{array}{l}\text { HPLC- } \\
\text {-ESI-MS/ } \\
\text { MS (QqQ) }\end{array}$ & 69 \\
\hline $\begin{array}{l}\text { COC, BE, EME, 6AM, } \\
\text { MTD, EDDP, AMP, MAMP } \\
\text { e MDMA }\end{array}$ & Esgoto bruto & $\begin{array}{l}\text { Acumulada em } \\
\text { função da vazão } \\
(24 \text { h) }\end{array}$ & $\begin{array}{l}\text { Acidificação a } \\
\text { pH } 2 \text { e armaze- } \\
\text { namento à }-20 \\
{ }^{\circ} \mathrm{C}\end{array}$ & $\begin{array}{l}50 \mathrm{~mL} \text { de amostra filtrada } \\
(\mathrm{FC}=250)\end{array}$ & $\begin{array}{l}\text { SPE com Oasis MCX (Wa- } \\
\text { ters) }\end{array}$ & $\begin{array}{l}\text { HPLC- } \\
\text { ESI-MS/ } \\
\text { MS (QqQ) }\end{array}$ & 68 \\
\hline $\begin{array}{l}\text { THC-COOH, COC, BE, } \\
\text { MOR, 6AM, COD, MTD, } \\
\text { EDDP }\end{array}$ & $\begin{array}{l}\text { Esgoto bruto, } \\
\text { efluente de ETE } \\
\text { e água superficial }\end{array}$ & $\begin{array}{l}\text { Esgoto e efluen- } \\
\text { te: acumulada em } \\
\text { função da vazão } \\
\text { (24 h) } \\
\text { Água superficial: } \\
\text { não informado } \\
\end{array}$ & $\begin{array}{l}\text { Acidificação a } \\
\text { pH 3, refrigera- } \\
\text { ção à } 4{ }^{\circ} \mathrm{C} \text { e ex- } \\
\text { tração em } 24 \mathrm{~h}\end{array}$ & $\begin{array}{l}100 \mathrm{~mL} \text { de esgoto }(\mathrm{FC}= \\
200), 250 \mathrm{~mL} \text { de efluente } \\
\text { de ETE }(\mathrm{FC}=500) \text { e } 500 \\
\mathrm{~mL} \text { de água superficial } \\
(\mathrm{FC}=1000) . \text { Amostras } \\
\text { filtradas }\end{array}$ & $\begin{array}{l}\text { SPE com Oasis MCX (Wa- } \\
\text { ters) }\end{array}$ & $\begin{array}{c}\text { HPLC- } \\
\text { ESI-MS/ } \\
\text { MS (QqQ) }\end{array}$ & 44 \\
\hline $\begin{array}{l}\text { COC, BE, CE, MOR, AMP, } \\
\text { MAMP e MDMA }\end{array}$ & Esgoto bruto & $\begin{array}{l}\text { Acumulada em } \\
\text { função da vazão } \\
(6 \mathrm{~h})\end{array}$ & Não informado & Variável & $\begin{array}{l}\text { Clean-up com Oasis MCX } \\
\text { (Waters) e extração passiva } \\
\text { (POCIS) com Oasis HLB } \\
\text { (Waters) }\end{array}$ & $\begin{array}{l}\text { UPLC- } \\
\text { ESI-MS/ } \\
\text { MS (QqQ) }\end{array}$ & 87 \\
\hline BE, MAMP e MDMA & Esgoto bruto & $\begin{array}{l}\text { Acumulada em } \\
\text { função da vazão } \\
(24 \mathrm{~h})\end{array}$ & $\begin{array}{l}\text { Armazenamento } \\
\text { à }-20^{\circ} \mathrm{C}\end{array}$ & $\begin{array}{l}300 \mathrm{~mL} \text { de amostra filtra- } \\
\text { da }(\mathrm{FC}=1875)\end{array}$ & $\begin{array}{l}\text { SPE com XtrackT DAU } \\
\text { (UCT) }\end{array}$ & $\begin{array}{c}\text { HPLC- } \\
\text {-ESI-MS/ } \\
\text { MS híbrido } \\
\text { (QqQ e IT) } \\
\end{array}$ & 48 \\
\hline COC, BE, AMP e MAMP & $\begin{array}{l}\text { Lodo de esgoto e } \\
\text { sedimento }(2 \mathrm{~cm})\end{array}$ & Instantânea & $\begin{array}{l}\text { Armazenamento } \\
\text { à }-20^{\circ} \mathrm{C}\end{array}$ & $1 \mathrm{a} 10 \mathrm{~g}$ de amostra & $\begin{array}{l}\text { Extração acelerada com sol- } \\
\text { vente }\end{array}$ & $\begin{array}{l}\text { UPLC- } \\
\text { ESI-MS/ } \\
\text { MS (QqQ) }\end{array}$ & 60 \\
\hline
\end{tabular}


Tabela 3. continuação,

\begin{tabular}{|c|c|c|c|c|c|c|c|}
\hline Analito & Matriz & Amostragem & Preservação & $\begin{array}{l}\text { Quantidade de amostra } \\
\text { e fator de concentração } \\
\text { (FC) }\end{array}$ & Extração & $\begin{array}{l}\text { Determina- } \\
\text { ção }\end{array}$ & Ref. \\
\hline $\begin{array}{l}\text { COC, BE, MOR, 6AM, } \\
\text { COD, HCOD }\end{array}$ & $\begin{array}{l}\text { Efluente de ETE } \\
\text { e água superficial }\end{array}$ & Não informado & Não informado & $\begin{array}{l}10 \text { a } 250 \mathrm{~mL} \text { de amostra } \\
\text { filtrada em sistema de } \\
\text { extração on-line (FC não } \\
\text { informado) }\end{array}$ & $\begin{array}{l}\text { Pré-coluna e SPE com fase } \\
\text { sólida sintetizada }\end{array}$ & $\begin{array}{l}\text { HPLC- } \\
\text {-ESI-MS }\end{array}$ & 45 \\
\hline $\begin{array}{l}\text { THC, THC-COOH, MOR, } \\
\text { COD, MTD, EDDP, AMP, } \\
\text { MAMP, MDA, MDMA e } \\
\text { MDEA }\end{array}$ & Esgoto bruto & $\begin{array}{l}\text { Acumulada em } \\
\text { função da vazão } \\
(24 \mathrm{~h})\end{array}$ & $\begin{array}{l}\text { Acidificação a } \\
\mathrm{pH} 2 \text { e armaze- } \\
\text { namento à }-20 \\
{ }^{\circ} \mathrm{C}\end{array}$ & $\begin{array}{l}200 \mathrm{~mL} \text { de amostra filtra- } \\
\text { da (FC não informado) e } \\
\text { injeção direta em HPLC- } \\
\text {-ESI-MS/MS }(400 \mu \mathrm{L})\end{array}$ & $\begin{array}{l}\text { SPE com Oasis MCX (Wa- } \\
\text { ters) }\end{array}$ & $\begin{array}{c}\text { HPLC- } \\
\text {-ESI-MS/ } \\
\text { MS híbrido } \\
\text { (QqQ e IT) }\end{array}$ & 71 \\
\hline $\begin{array}{l}\text { COC, ECG, BE, EME, CE, } \\
\text { AE, AEME, Nor-BE e Nor- } \\
\text { COC }\end{array}$ & Esgoto bruto & $\begin{array}{l}\text { Acumulada em } \\
\text { função da vazão } \\
(24 \mathrm{~h})\end{array}$ & $\begin{array}{l}\text { Armazenamento } \\
\text { à }-20^{\circ} \mathrm{C}\end{array}$ & $\begin{array}{l}20 \mathrm{~mL} \text { de amostra filtrada } \\
(\mathrm{FC}=2000)\end{array}$ & $\begin{array}{l}\text { SPE com Oasis HLB, Oasis } \\
\text { MCX, Oasis MAX, Oasis } \\
\text { WCX (Waters), Evolute ABN } \\
\text { (Biotage), }\end{array}$ & $\begin{array}{c}\text { HPLC- } \\
\text { ESI-MS/ } \\
\text { MS (QqQ) }\end{array}$ & 32 \\
\hline $\begin{array}{l}\text { COC, ECG, BE, CE, AEME, } \\
\text { Nor-COC, Nor-BE, MOR, } \\
\text { 6AM, Nor-MOR, COD, } \\
\text { MTD, EDDP, AMP, MAMP, } \\
\text { MDA, MDMA, MDEA, } \\
\text { MBDB, LSD, O-H-LSD }\end{array}$ & $\begin{array}{l}\text { Esgoto bruto, } \\
\text { efluente de ETE } \\
\text { e água superficial }\end{array}$ & Instantânea & $\begin{array}{l}\text { Filtração, acidi- } \\
\text { ficação a pH 2, } \\
\text { refrigeração à } \\
4{ }^{\circ} \mathrm{C} \text { e extração } \\
\text { em } 20 \mathrm{~h}\end{array}$ & $\begin{array}{l}100 \mathrm{~mL} \text { de esgoto e } \\
\text { efluente de ETE }(\mathrm{FC}= \\
\text { 200) e } 500 \mathrm{~mL} \text { de água } \\
\text { superficial }(\mathrm{FC}=1000) . \\
\text { Amostras filtradas }\end{array}$ & $\begin{array}{l}\text { SPE com Oasis MCX (Wa- } \\
\text { ters) }\end{array}$ & $\begin{array}{l}\text { UPLC- } \\
\text { ESI-MS/ } \\
\text { MS (QqQ) }\end{array}$ & 19 \\
\hline
\end{tabular}

e outros

\begin{tabular}{|c|c|c|c|c|c|c|c|}
\hline $\mathrm{COC}$ e $\mathrm{BE}$ & Esgoto bruto & $\begin{array}{l}\text { Acumulada em } \\
\text { função da vazão }\end{array}$ & Não informado & $\begin{array}{l}500 \mathrm{~mL} \text { de amostra filtra- } \\
\text { da em } G C-M S \text { (FC aprox. } \\
7500) \text { e injeção direta } \\
\text { em } H P L C \text { - } E S I-M S / M S \\
(1000 \mu \mathrm{L})\end{array}$ & $\begin{array}{l}\text { SPE com Oasis MCX (Wa- } \\
\text { ters) }\end{array}$ & $\begin{array}{c}\text { HPLC- } \\
\text { ESI-MS/ } \\
\text { MS (QqQ) } \\
\text { e GC-MS }\end{array}$ & 30 \\
\hline COC, BE e MAMP & Esgoto bruto & Acumulada $(6 \mathrm{~h})$ & $\begin{array}{l}\text { Acidificação a } \\
\text { pH } 3,5\end{array}$ & Não informado & $\begin{array}{l}\text { SPE com Oasis MCX (Wa- } \\
\text { ters) }\end{array}$ & $\begin{array}{c}\text { UPLC- } \\
\text { ESI-MS/ } \\
\text { MS (QqQ) }\end{array}$ & 88 \\
\hline $\mathrm{COC}, 6 \mathrm{AM}, \mathrm{COD}$ e EDDP & $\begin{array}{l}\text { Água superficial } \\
\text { e ág ua para } \\
\text { consumo }\end{array}$ & Não informado & $\begin{array}{l}\text { Filtração, ar- } \\
\text { mazenamento a } \\
-18{ }^{\circ} \mathrm{C} \text { e extra- } \\
\text { ção em } 72 \mathrm{~h}\end{array}$ & Não informado & $\begin{array}{l}\text { SPE com Oasis HLB (Wa- } \\
\text { ters) em sistema eletrofo- } \\
\text { rético }\end{array}$ & CE-UV & 89 \\
\hline $\begin{array}{l}\text { THC, THC-COOH, COC, } \\
\text { BE, CE, HER, MOR, 6AM, } \\
\text { COD, PCP, MTD, EDDP, } \\
\text { AMP, MAMP, MDA, } \\
\text { MDMA, MDEA, LSD e } \\
\text { O-H-LSD }\end{array}$ & $\begin{array}{l}\text { Esgoto bruto e } \\
\text { efluente de esgoto }\end{array}$ & $\begin{array}{l}\text { Instantânea e acu- } \\
\text { mulada (24) }\end{array}$ & Extração em $6 \mathrm{~h}$ & $\begin{array}{l}200 \mathrm{~mL} \text { de esgoto }(\mathrm{FC}= \\
400) \text { e } 500 \mathrm{~mL} \text { de efluente } \\
\text { de ETE }(\mathrm{FC}=1000) \\
\text { Amostras filtradas. }\end{array}$ & $\begin{array}{l}\text { SPE com Oasis MCX (Wa- } \\
\text { ters) }\end{array}$ & $\begin{array}{l}\text { HPLC- } \\
\text { ESI-MS/ } \\
\text { MS } \\
\text { (QTOF) }\end{array}$ & 90 \\
\hline $\begin{array}{l}\text { THC, THC-COOH, OH- } \\
\text { THC, COC, BE, CE, HER, } \\
\text { MOR, 6AM, MTD, EDDP, } \\
\text { AMP, MAMP e MDMA }\end{array}$ & Água subterrânea & Não informado & $\begin{array}{l}\text { Armazenamento } \\
\text { no escuro }\end{array}$ & $\begin{array}{l}5 \mathrm{~mL} \text { de amostra filtrada } \\
\text { em sistema de extração } \\
\text { on-line (FC não infor- } \\
\text { mado) }\end{array}$ & $\begin{array}{l}\text { SPE com fase polimérica } \\
\text { PLRP (Spark Holland) }\end{array}$ & $\begin{array}{l}\text { HPLC- } \\
\text {-ESI-MS/ } \\
\text { MS (QqQ) }\end{array}$ & 61 \\
\hline $\begin{array}{l}\text { AMP, MAMP, MDA e } \\
\text { MDMA }\end{array}$ & Esgoto bruto & Instantânea & Não informado & $\begin{array}{l}100 \mathrm{~mL} \text { de amostra filtra- } \\
\text { da }(\mathrm{FC}=200)\end{array}$ & $\begin{array}{l}\text { SPE com Oasis HLB (Wa- } \\
\text { ters) }\end{array}$ & $\begin{array}{c}\text { UPLC- } \\
\text { ESI-MS/ } \\
\text { MS (QqQ) }\end{array}$ & 72 \\
\hline $\begin{array}{l}\text { THC, THC-COOH, OH- } \\
\text { THC, COC, BE, CE, Nor- } \\
\text { BE, HER, MOR, 6AM, } \\
\text { MTD, EDDP, AMP, MAMP, } \\
\text { MDMA, LSD, nor-LSD, O- } \\
\text { H-LSD e outros }\end{array}$ & $\begin{array}{l}\text { Água superficial } \\
\text { e ág u a para } \\
\text { consumo }\end{array}$ & Instantânea & $\begin{array}{l}\text { Filtração e ar- } \\
\text { mazenamento } \\
\text { no escuro em } \\
\text { frasco PET à } \\
-20^{\circ} \mathrm{C}\end{array}$ & $\begin{array}{l}5 \mathrm{~mL} \text { de amostra filtrada } \\
\text { em sistema de extração } \\
\text { on-line (FC não infor- } \\
\text { mado) }\end{array}$ & $\begin{array}{l}\text { SPE com Oasis HLB (Wa- } \\
\text { ters) e fase polimérica PLRP } \\
\text { (Spark Holland) }\end{array}$ & $\begin{array}{c}\text { HPLC- } \\
\text {-ESI-MS/ } \\
\text { MS híbrido } \\
\text { (QqQ e IT) }\end{array}$ & 51 \\
\hline $\mathrm{COC}$ e BE & Esgoto bruto & $\begin{array}{l}\text { Acumulada em } \\
\text { função da vazão } \\
(12 \mathrm{~h}+12 \mathrm{~h})\end{array}$ & $\begin{array}{l}\text { Refrigeração à } 4 \\
{ }^{\circ} \mathrm{C} \text { e extração em } \\
3 \text { dias }\end{array}$ & $\begin{array}{l}200 \mathrm{~mL} \text { de amostra filtra- } \\
\text { da }(\mathrm{FC}=200)\end{array}$ & $\begin{array}{l}\text { SPE com Oasis HLB (Wa- } \\
\text { ters) }\end{array}$ & $\begin{array}{l}\text { HPLC- } \\
\text { ESI-MS/ } \\
\text { MS (QqQ) }\end{array}$ & 31 \\
\hline
\end{tabular}

HPLC: cromatografia líquida de alta eficiência, UPLC: cromatografia líquida de ultraeficiência, GC: cromatografia gasosa, ESI: ionização por eletrospray, API: ionização à pressão atmosférica, MS: espectrômetro de massas, MS/MS: espectrômetro de massas in tandem, QqQ: triplo quadrupolo, IT: ion-trap, CE-UV: eletroforese capilar acoplada à espectrofotometria na região do UV.

de extração baseados em extração passiva do tipo POCIS (Polar Organic Chemical Integrative Sampler $)^{4,82,87}$ ou ainda a injeção direta da amostra em cromatógrafos líquidos de alta ou ultraeficiência (HPLC ou UPLC, respectivamente), ambos operando com espectrômetros de massas in tandem (MS/MS) do tipo triplo quadrupolos (QqQ) ${ }^{18,50}$ Chiaia e colaboradores, ${ }^{18}$ por exemplo, empregaram com êxito uma técnica denominada LVI (large-volume injection) que se baseia na injeção direta de volumes entre 100 a $5000 \mu \mathrm{L}$ no equipamento. Nesse estudo, o objetivo foi eliminar a etapa de extração, por vezes inexata, e determinar 22 substâncias-alvo, dentre as quais COC e AMP, em amostras de esgoto bruto.

Bisceglia e colaboradores ${ }^{53}$ compararam a utilização da SPE como etapa de pré-tratamento de amostras com a injeção direta do esgoto bruto em equipamento HPLC-MS/MS equipado com interface de ionização por eletronebulização (ESI, electrospray ionization). Mesmo com o potencial aumento dos efeitos de matriz, os valores de concentração determinados pelos dois métodos apresentaram boa concordância, com exceção de 7 das 24 substâncias de interesse 
que apresentaram erros relativos maiores que $20 \%$ para as amostras analisadas por injeção direta.

\section{Determinação analítica}

A identificação e/ou quantificação das drogas de abuso e de seus metabólitos em diferentes matrizes aquáticas tem sido realizada por meio de técnicas analíticas de separação, tais como cromatografia gasosa, cromatografia líquida de alta eficiência e cromatografia líquida de ultraeficiência acopladas, na vasta maioria das vezes, a espectrômetros de massas. Espectrômetros com analisadores de massas do tipo quadrupolo, captura de íons (IT, ion-trap), tempo de vôo (TOF, time-of-flight), simples, híbridos ou ainda do tipo in tandem, como os triplo quadrupolos, podem ser empregados para a investigação sobre o conteúdo de drogas de abuso em águas superficiais e residuárias. Entretanto, a vasta maioria dos trabalhos publicados desde 2004 e mostrados na Tabela 3, lança mão de cromatografia líquida acoplada à espectrometria de massas em triplo quadrupolo [HPLC ou UPLCMS/MS (QqQ)], que responde por cerca de 70\% dos trabalhos publicados sobre o tema devido, principalmente, à grande sensibilidade, seletividade e rapidez na aquisição de dados. O diferencial desta técnica hifenada está na utilização de duas etapas de espectrometria de massas no monitoramento de íons específicos de cada substância de interesse e de seus fragmentos. Desta maneira, a interferência de substâncias presentes na matriz é drasticamente reduzida, podendo levar a limites de detecção (LD) e de quantificação (LQ) compatíveis com as concentrações encontradas nas amostras. ${ }^{10}$

\section{CONSIDERAÇÕES FINAIS}

Além dos problemas notórios referentes ao consumo abusivo de drogas, novas evidências têm revelado uma faceta ambiental frente à presença destas substâncias no dia-a-dia de grandes cidades. Drogas de abuso de diferentes classes, assim como seus produtos de metabolização e/ou biotransformação, têm sido recentemente encontradas em amostras de diferentes compartimentos ambientais. A ocorrência destas substâncias em águas naturais implica em condições inadequadas de gerenciamento de resíduos urbanos, uma vez que o esgoto bruto surge como vetor majoritário de contaminação de águas, assim como ocorre para outros contaminantes emergentes.

Ainda se sabe pouco sobre a ecotoxicidade destes contaminantes e menos ainda sobre um possível quadro de exposição crônica de organismos em desenvolvimento, incluindo seres humanos, frente à água contendo traços de drogas de abuso e metabólitos. Por outro lado, a ocorrência destas substâncias no esgoto bruto tem servido como ferramenta para se estimar o consumo de uma população, visto que, geralmente, a obtenção de informações confiáveis sobre tráfico e consumo de drogas é subjetiva e limitada pela própria natureza ilícita da atividade. Esta nova abordagem forense, denominada epidemiologia do esgoto, avança a passos largos para se consolidar como uma poderosa ferramenta para obtenção de informações em tempo real sobre consumo e produção de drogas, somando-se aos métodos tradicionais de coleta de dados. As possibilidades de aplicação dessa nova ferramenta são inúmeras e somente a contribuição da Química, juntamente com disciplinas correlatas, permitirá que epidemiologia do esgoto tenha todo o seu potencial explorado.

\section{AGRADECIMENTOS}

Ao Instituto Nacional de Ciências e Tecnologias Analíticas Avançadas (INCTAA) e ao Conselho Nacional de Desenvolvimento Científico e Tecnológico (Proc. 402783/2010-7) pelo auxílio financeiro para o desenvolvimento de estudos sobre drogas de abuso no ambiente.

\section{REFERÊNCIAS}

1. Ternes, T. A.; Water Res. 1998, 32, 3245; Sadik, O. A.; Witt, D. M.; Environ. Sci. Technol. 1999, 33, 368A; Hirsch, R.; Ternes, T.; Haberer, K.; Kratz, K. L.; Sci. Total Environ. 1999, 225, 109; Bila, D. M.; Dezotti, M.; Quim. Nova 2007, 30, 651; Ghiselli, G.; Jardim, W. F.; Quim. Nova 2007, 30, 695 .

2. la Farré, M.; Pérez, S.; Kantiani, L.; Barceló, D.; Trends Anal. Chem. 2008, 27, 991; Díaz-Cruz, M. S.; García-Galán, M. J.; Guerra, P.; Jelic, A.; Postigo, C.; Eljarrat, E.; la Farré, M.; López de Alda, M. J.; Petrovic, M.; Barceló, D.; Trends Anal. Chem. 2009, 28, 1263.

3. Toppari, J.; Larsen, P.; Christiansen, P.; Giwercman, A.; Grandjean, P.; Guillette Jr, L. J.; Jégou, B.; Jensen, T. K.; Jouannet, P.; Keiding, N.; Leffers, H.; McLachlan, J. A.; Meyer, O.; Müller, J.; Meyts, E. R.-D.; Scheike, T.; Sharpe, R.; Sumpter, J.; Skakkebæk1, N. E.; Environ. Health Perspect. 1996, 104, 741; Kidd, K. A.; Blanchfield, P. J.; Mills, K. H.; Palace, V. P.; Evans, R. E.; Lazorchak, J. M.; Flick, R. W.; Proc. Natl. Acad. Sci. U.S.A. 2007, 104, 8897; Bergamasco, A. M. D.; Eldridge, M. L.; Sanseverino, J.; Sodré, F. F.; Montagner, C. C.; Pescara, I. C.; Jardim, W. F.; Umbuzeiro, G. A.; J. Environ. Monit. 2011, 13, 3288 .

4. Jones-Lepp, T. L.; Alvarez, D. A.; Petty, J. D.; Huckins, J. N.; Arch. Environ. Contam. Toxicol. 2004, 47, 427.

5. Zuccato, E.; Chiabrando C.; Castiglioni, S.; Calamari, D.; Bagnati, R.; Schiarea, S.; Fanelli, R.; Environ. Health-Glob. 2005, 4, 14.

6. Huerta-Fontela, M.; Galceran, M. T.; Martin-Alonso, J.; Ventura, F.; Sci. Total Environ. 2008, 397, 31.

7. Petrovic, M.; Radjenovic, J.; Postigo, C.; Kuster, M.; Farre, M.; López de Alda, M.; Barceló, D. Em Emerging Contaminants from Industrial and Municipal Waste: Ocurrence, Analysis and Effects; Barceló, D.; Petrovic, M., eds.; Springer: Berlim, 2008, chap. 1.

8. Postigo, C.; López de Alda, M. J.; Barceló, D.; Environ. Int. 2010, 36, 75.

9. Pomati, F.; Castiglioni, S.; Zuccato, E.; Fanelli, R.; Vigetti, D.; Rossetti, C.; Calamari, D.; Environ. Sci. Technol. 2006, 40, 2442.

10. UNODC; The world drug report 2011, United Nations Office of Drugs and Crime: Viena, 2011.

11. Portaria SVS/MS No 344, de 12/05/1998, Diário Oficial da União, Brasília, 01/02/1999; Resolução RDC No 37, de 02/07/2012, Diário Oficial da União, Brasília, 03/07/2012.

12. http://www.planalto.gov.br/ccivil_03/_ato2004-2006/2006/lei/111343. htm, acessada em Janeiro 2013.

13. EMCDDA; Assessing illicit drugs in wastewater - Potential and limitations of a new monitoring approach, European Monitoring Centre for Drugs and Drug Addiction: Luxemburgo, 2008.

14. http://www.obid.senad.gov.br/portais/OBID/biblioteca/documentos/ Publicacoes/327615.pdf, acessada em Janeiro 2013.

15. Zuccato, E.; Castiglioni, S.; Bagnati, R.; Chiabrando, C.; Grassi, P.; Fanelli, R.; Water Res. 2008, 42, 961.

16. Zuccato, E.; Castiglioni, S.; Fanelli, R.; Reitano, G.; Bagnati, R.; Chiabrando, C.; Pomati, F.; Rossetti, C.; Calamari, D.; Environ. Sci. Pollut. Res. 2006, 13, 15.

17. Postigo, C.; López de Alda, M. J.; Barceló, D.; Anal. Chem. 2008, 80, 3123.

18. Chiaia, A. C.; Banta-Green, C.; Field, J.; Environ. Sci. Technol. 2008, 42,8841 .

19. Baker, D. R.; Kasprzyk-Hordern, B.; J. Chromatogr., A 2011, 1218, 1620 .

20. Moffat, A. C.; Osselton, M. D.; Widdop, B.; Clarke's Analysis of Drugs and Poisons: in pharmaceuticals, body fluids, and postmortem material, $3^{\text {rd }}$ ed., Pharmaceutical Press: London, 2004.

21. Baird, C.; Cann, M.; Química Ambiental, $4^{\mathrm{a}}$ ed., Bookman: Porto Alegre, 2011. 
22. http://portal.saude.gov.br/portal/arquivos/pdf/cap_4_mecanismos_de_ transporte.pdf, acessada em Janeiro 2013.

23. Zuin, V. G.; Ioriatti, M. C. S.; Matheus, C. E,; Química Nova na Escola 2009, 31, 3.

24. Sage, M. L.; Sage, G. W.; Mackay, D.; Shiu, W. Y.; Ma, K. C. Em Handbook of Property Estimation Methods for Chemicals: Environmental and Health Sciences; Mackay, D.; Boethling, R. S., eds.; CRC Press LLC: Boca Raton, 2000, chap. 3 e 4.

25. Domènech, X.; Peral, J.; Muñoz, I.; Water Res. 2009, 43, 5236.

26. Hannigan, M. P.; Cass, G. R.; Penman, B. W.; Crespi, C. L.; Lafleur, A. L.; Busby, W. F.; Thilly, W. G.; Simoneit, B. R. T.; Environ. Sci. Technol. 1998, 32, 3502.

27. Bila, D. M.; Dezotti, M.; Quim. Nova 2003, 26, 523; Paschoalino, M. P.; Marcone, G. P. S.; Jardim, W. F.; Quim. Nova 2010, 33, 421; Sodré, F. F.; Pescara, I. C.; Montagner, C. C.; Jardim, W. F.; Microchem. J. 2010, 96, 92; Sodré, F. F.; Locatelli, M. A. F.; Jardim, W. F.; Water, Air, Soil Pollut. 2010, 206, 57; Locatelli, M. A. F.; Sodré, F. F.; Jardim, W. F.; Arch. Environ. Contam. Toxicol. 2011, 60, 385; Montagner, C. C.; Jardim, W. F.; J. Braz. Chem. Soc. 2011, 22, 1452.

28. Huerta-Fontela, M.; Galceran, M. T.; Ventura, F.; Environ. Sci. Technol. 2008, 42, 6809 .

29. http://www.scopus.com/search/form.url, acessada em Agosto 2012.

30. Mathieu, C.; Rieckermann, J.; Berset, J. D.; Schürch, S.; Brenneisen, R.; Water Res. 2011, 45, 6650

31. Maldaner, A. O.; Schmidt, L. L.; Locatelli, M. A. F.; Jardim, W. F.; Sodré, F. F.; Almeida, F. V.; Pereira, C. E. B.; Silva, C. M.; J. Braz. Chem. Soc. 2012, 23, 861.

32. Castiglioni, S.; Bagnati, R.; Melis, M.; Panawennage, D.; Chiarelli, P.; Fanelli, R.; Zuccato, E.; Water Res. 2011, 45, 5141.

33. Metcalfe, C.; Tindale, K.; Li, H.; Rodayan, A.; Yargeau, V.; Environ. Pollut. 2010, 158, 3179

34. Gheorghe, A.; van Nuijs, A.; Pecceu, B.; Bervoets, L.; Jorens, P. G.; Blust, R.; Neels, H.; Covaci, A.; Anal. Bioanal. Chem. 2008, 391, 1309.

35. Bonés, J.; Thomas, K. V.; Paull, B.; J. Environ. Monit. 2007, 9, 701.

36. Martínez-Bueno, M. J.; Uclés, S.; Hernando, M. D.; Fernández-Alba, A. R.; Talanta 2011, 85, 157.

37. Castiglioni, S.; Zuccato, E.; Crisci, E.; Chiabrando, C.; Fanelli, R.; Bagnati, R.; Anal. Chem. 2006, 78, 8421.

38. van Nuijs, A. L. N.; Tarcomnicu, I.; Bervoets, L.; Blust, R.; Jorens, P. G.; Neels, H.; Covaci, A.; Anal. Bioanal. Chem. 2009, 395, 819.

39. Huerta-Fontela, M.; Galceran, M. T.; Ventura, F.; Anal. Chem. 2007, 79, 3821.

40. Terzic, S.; Senta, I.; Ahel, M.; Environ. Pollut. 2010, 158, 2686.

41. González-Mariño, I.; Quintana, J. B.; Rodríguez, I.; Cela, R.; J. Chromatogr., A 2010, 1217, 1748.

42. Mari, F.; Politi, L.; Biggeri, A.; Accetta, G.; Trignano, C.; Di Pádua, M.; Berto, E. L.; Forensic Sci. Int. 2009, 189, 88.

43. Karolak, S.; Nefau, T.; Bailly, E.; Solgadi, A.; Levi, Y.; Forensic Sci. Int. 2010, 200, 153.

44. Pedrouzo, M.; Borrull, F.; Pocurull, E.; Marcé, R. M.; J. Sep. Sci. 2011, 34, 1091.

45. Fontanals, N.; Marcé, R. M.; Borrull, F.; J. Chromatogr., A 2011, 1218, 5975.

46. van Nuijs, A. L. N.; Pecceu, B.; Theunis, L.; Dubois, N.; Charlier, C.; Jorens, P. G.; Bervoets, L.; Blust, R.; Neels, H.; Covaci, A.; Environ. Pollut. 2009, 157, 123.

47. Kasprzyk-Hordern, B.; Dinsdale, R. M.; Guwy, A. J.; Water Res. 2008, $42,3498$.

48. Irvine, R. J.; Kostakis, C.; Felgate, P. D.; Jaehne, E. J.; Chen, C.; White, J. M.; Forensic Sci. Int. 2011, 210, 69.

49. Hummel, D.; Löffler, D.; Fink, G.; Ternes, T. A.; Environ. Sci. Technol. 2006, 40, 7321.

50. Berset, J. D.; Brenneise, R.; Mathieu, C.; Chemosphere 2010, 81, 859.
51. Valcárcel, Y.; Martínez, F.; González-Alonso, S.; Segura, Y.; Catalá, M.; Molina, R.; Montero-Rubio, J. C.; Mastroianni, N.; López de Alda, M.; Postigo, C.; Barceló, D.; Environ. Int. 2012, 41, 35.

52. Vazquez-Roig, P.; Andreu, V.; Blasco, C.; Picó, Y.; Anal. Bioanal. Chem. 2010, 397, 2851.

53. Bisceglia, K. J.; Roberts, A. L.; Schantz, M. M.; Lippa, K. A.; Anal. Bioanal. Chem. 2010, 398, 2701.

54. Boleda, M. R.; Galceran, M. T.; Ventura, F.; Water Res. 2009, 43, 1126.

55. Cecinato, A.; Balducci, C.; J. Sep. Sci. 2007, 30, 1930

56. Viana, M.; Postigo, C.; Querol, X.; Alastuey, A.; López de Alda, M. J.; Barceló, D.; Artinano, B.; López-Mahia, P.; Gacio, D. G.; Cots, N.; Environ. Pollut. 2011, 159, 1241.

57. Postigo, C.; López de Alda, M. J.; Viana, M.; Querol, X.; Alastuey, A.; Artinano, B.; Barceló, D.; Anal. Chem. 2009, 81, 4382; Cecinato, A.; Balducci, C.; Nervegna, G.; Tagliacozzo, G.; Allegrini, I.; J. Environ. Monit. 2009, 11, 200; Balducci, C.; Nervegna, G.; Cecinato, A.; Anal. Chim. Acta 2009, 641, 89; Viana, M.; Querol, X.; Alastuey, A.; Postigo, C.; López de Alda, M. J.; Barceló, D.; Artinano, B.; Environ. Int. 2010, 36, 527; Cecinato, A.; Balducci, C.; Budetta, V.; Pasini, A.; Atmos. Environ. 2010, 44, 2358.

58. Kaleta, A.; Ferdig, M.; Buchberger, W.; J. Sep. Sci. 2006, 29, 1662.

59. Jones-Lepp, T. L.; Stevens, R.; Anal. Bioanal. Chem. 2007, 387, 1173.

60. Langford, K. H.; Reid, M.; Thomas, K. V.; J. Environ. Monit. 2011, 13, 2284.

61. Jurado, A.; Mastroianni, N.; Vàzquez-Suñé, E.; Carrera, J.; Tubau, I.; Pujades, E.; Postigo, C.; López de Alda, M.; Barceló, D.; Sci. Total Environ. 2012, 424, 280.

62. Boleda, M. R.; Huerta-Fontela, M.; Ventura, F.; Galceran, M. T.; Chemosphere 2011, 84, 1601.

63. Daughton, C. G. Em Pharmaceuticals and Personal Care Products in the Environment: Scientific and Regulatory Issues; Daughton, C. G.; Jones-Lepp, T. L., eds.; American Chemical Society: Washington, D.C., 2001, chap. 20

64. Daughton, C. G.; Rev. Environ. Contam. Toxicol. 2011, 210, 59.

65. van Nuijs, A. L. N.; Mougel, J-F.; Tarcomnicu, I.; Bervoets, L.; Blust, R.; Jorens, P. G.; Neels, H.; Covaci, A.; Environ. Int. 2011, 37, 612.

66. van Nuijs, A. L. N.; Castiglioni, S.; Tarcomnicu, I.; Postigo, C.; López de Alda, M.; Neels, H.; Zuccato, E.; Barceló, D.; Covaci, A.; Sci. Total Environ. 2011, 409, 3564.

67. Zuccato, E.; Castiglioni, S.; Philos. T R Soc. A 2009, 367, 3965.

68. van Nuijs, A. L. N.; Mougel, J. F.; Tarcomnicu, I.; Bervoets, L.; Blust, R.; Jorens, P. G.; Neels, H.; Covaci, A.; J. Environ. Monit. 2011, 13, 1008 .

69. Postigo, C.; López de Alda, M.; Barceló, D.; Environ. Int. 2011, 37, 49.

70. Khan, U.; Nicell, J. A.; Environ. Int. 2011, 37, 1236.

71. Lai, F. Y.; Ort, C.; Gartner, C.; Carter, S.; Prichard, J.; Kirkbride, P.; Bruno, R.; Hall, W.; Eaglesham, G.; Mueller, J. F.; Water Res. 2011, 45, 4437.

72. Kasprzyk-Hordern, B.; Baker, D. R.; Sci. Total Environ. 2012, 423, 142.

73. Kasprzyk-Hordern, B.; Chem. Soc. Rev. 2010, 39, 4466; KasprzykHordern, B.; Kondakal, V. V. R.; Baker, D. R.; J. Chromatogr., A 2010, 1217,4575 .

74. Kasprzyk-Hordern, B.; Baker, D. R.; Environ. Sci. Technol. 2012, 46, 1681.

75. Kasprzyk-Hordern, B.; Dinsdale, R. M.; Guwy, A. J.; J Chromatogr., A 2007, 1161, 132

76. Kasprzyk-Hordern, B.; Dinsdale, R. M.; Guwy, A. J.; Anal. Bioanal. Chem. 2008, 391, 1293.

77. Zuccato, E.; Chiabrando, C.; Castiglioni, S.; Bagnati, R.; Fanelli, R.; Environ. Health Persp. 2008, 116, 1027.

78. Theunis, L.; van Nuijs, A. L. N.; Pecceu, B.; Dubois, N.; Jorens, P. G.; Bervoets, L.; Blust, R.; Neels, H.; Covaci, A.; Charlier, C.; Rev. Med. Liège 2008, 63, 39. 
79. Kasprzyk-Hordern, B.; Dinsdale, R. M.; Guwy, A. J.; Water Res. 2009, $43,363$.

80. Loganathan, B.; Phillips, M.; Mowery, H.; Jones-Lepp, T. L.; Chemosphere 2009, 75, 70 .

81. van Nuijs, A. L. N.; Pecceu, B.; Theunis, L.; Dubois, N.; Charlier, C.; Jorens, P. G.; Bervoets, L.; Blust, R.; Neels, H.; Covaci, A.; Water Res. 2009, 43, 1341.

82. Bartelt-Hunt, S. L.; Snow, D. D.; Damon, T.; Shockley, J.; Hoagland, K.; Environ. Pollut. 2009, 157, 786.

83. van Nuijs, A. L. N.; Pecceu, B.; Theunis, L.; Dubois, N.; Charlier, C.; Jorens, P. G.; Bervoets, L.; Blust, R.; Meulemans, H.; Neels, H.; Covaci, A.; Addiction 2009, 104, 734.

84. Kasprzyk-Hordern, B.; Dinsdale, R. M.; Guwy, A. J.; Environ. Pollut. 2009, 157, 1773
85. Bijlsma, L.; Sancho, J. V.; Pitarch, E.; Ibáñez, M.; Hernández, F.; J. Chromatogr., A 2009, 1216, 3078.

86. Lin, A. Y. -C.; Wang, X. -H.; Lin, C. -F.; Chemosphere 2010, 81, 562.

87. Harman, C.; Reid, M.; Thomas, K. V.; Environ. Sci. Technol. 2011, 45, 5676.

88. Reid, M. J.; Langford, K. H.; Mørland, J.; Thomas, K. V.; Drug Alcohol Depen. 2011, 119, 179.

89. Botello, I.; Borrull, F.; Aguilar, C.; Calull, M.; Electrophoresis 2012, 33, 528.

90. González-Mariño, I.; Quintana, J. B.; Rodríguez, I.; González-Díez, M.; Cela, R.; Anal. Chem. 2012, 84, 1708.

91. González-Mariño, I.; Quintana, J. B.; Rodriguez, I.; Rodil, R.; GonzalezPenas, J.; Cela, R.; J. Chromatogr., A 2009, 1216, 8435. 